\title{
Modification of the Structural, Microstructural, and Elastoplastic Properties of Aluminum Wires after Operation
}

\author{
Aleksandr A. Levin ${ }^{1, *}{ }^{\circledR}$, Maria V. Narykova ${ }^{1}$, Alexey I. Lihachev ${ }^{1}$, Boris K. Kardashev ${ }^{1}$, \\ Andrej G. Kadomtsev ${ }^{1}$, Pavel N. Brunkov ${ }^{1}{ }^{1}$, Andrei G. Panfilov ${ }^{1}$, Nikita D. Prasolov ${ }^{1}{ }^{1}$, Makhsud M. Sultanov ${ }^{2}$, \\ Vasily N. Kuryanov ${ }^{2}$ and Vladimir N. Tyshkevich ${ }^{2}$ (D) \\ 1 Ioffe Institute, Politekhnicheskaya ul. 26, 194021 St. Petersburg, Russia; \\ Maria.Narykova@mail.ioffe.ru (M.V.N); Lihachev@mail.ioffe.ru (A.I.L.); B.Kardashev@mail.ioffe.ru (B.K.K.); \\ Andrej.Kadomtsev@mail.ioffe.ru (A.G.K.); brunkov@mail.ioffe.ru (P.N.B.); a.panfilov@mail.ioffe.ru (A.G.P.); \\ Nikpras@mail.ioffe.ru (N.D.P.) \\ 2 Moscow Power Engineering Institute, National Research University, Volzhsky Branch, Lenina pr. 69, \\ 404110 Volzhsky, Russia; sultanov_mm@mail.ru (M.M.S.); vek077@yandex.ru (V.N.K.); \\ tubem@mail.ru (V.N.T.) \\ * Correspondence: aleksandr.a.levin@mail.ioffe.ru
}

Citation: Levin, A.A.; Narykova M.V.; Lihachev, A.I.; Kardashev, B.K.; Kadomtsev, A.G.; Brunkov, P.N.; Panfilov, A.G.; Prasolov, N.D.; Sultanov, M.M.; Kuryanov, V.N.; et al. Modification of the Structural, Microstructural, and Elastoplastic Properties of Aluminum Wires after Operation. Metals 2021, 11, 1955. https://doi.org/10.3390/met11121955

Academic Editor: Babak Shalchi Amirkhiz

Received: 7 November 2021

Accepted: 1 December 2021

Published: 5 December 2021

Publisher's Note: MDPI stays neutral with regard to jurisdictional claims in published maps and institutional affiliations.

Copyright: (c) 2021 by the authors. Licensee MDPI, Basel, Switzerland. This article is an open access article distributed under the terms and conditions of the Creative Commons Attribution (CC BY) license (https:/ / creativecommons.org/licenses/by/ $4.0 /)$.
Abstract: The health of the components that make up the cables of power lines, and hence their service life, is governed at the micro level by changes in their structure and microstructure. In this paper, the structure and microstructure of aluminum wires of overhead power transmission lines (without a steel core) of different service life from 0 to 62 years have been investigated by quantitative techniques of X-ray diffraction, diffraction of back-scattered electrons, and the densitometric method. Elastoplastic properties of the wires have been tested by the acoustic-resonance method. A decrease in the $\mathrm{Al}$ material density $\Delta \rho / \rho \sim-0.165 \%$ was found in the near-surface layer of $\sim 36 \mu \mathrm{m}$ depth and in the bulk of the wires with an increase in the service life from 0 to 18 years. The density decrease is associated with the accumulation of microcracks. The following density increase $(\Delta \rho / \rho \sim-0.06 \%)$ in wires with a service life of 62 years is attributed to the formation of $\sim 0.7$ vol. $\%$ of crystalline $\mathrm{Al}$ oxides in the near-surface layers of the wires. The nature of the change in the elastic modulus, microplastic flow stress, and decrement indicates complex structural changes correlating with the results obtained by diffraction methods.

Keywords: aluminum wires; overhead power lines; XRD; EBSD; elastoplastic properties; density; crystallites; grains

\section{Introduction}

Power cables are the most important items of the distribution and transmission infrastructure of electrical networks, being laid in different environments such as air [1-3], underwater [4], or underground [5,6]. Power cables are also used under the influence of ionizing radiation at nuclear power plants [7].

Cables can contain one or more multi-wire strands of highly conductive materials, usually aluminum in the case of air cables [1-3] or copper $[4,6,7]$ in the case of either submarine or underground cables or cables at nuclear power plants. In the case of multiple multi-wire strands in the cable, the strands are insulated from each other with polymer coating [4,6,7]. Cables with one multi-wire strand can be used bare, i.e., without isolation [2] or can be clad in insulating plastic protective coat to increase their service life by minimizing the possibility of short circuits due to contact either between cables of different phases, or with trees in the forest, or atmospheric icing, and so on (see [1,8,9] and references therein). To increase the service life of overhead power transmission cables, steel cores are often used to mitigate the effects of mechanical stress on cables [2].

Mechanical loads on wires of overhead power lines are of a repeatedly variable nature and, over time, can lead to fatigue failure of either individual conducting wires in a whole 
twist of an aluminum multi-wire strand or to rupture of the entire stranded thread. Besides, the fatigue resistance of a wire depends not only on the fatigue resistance of the wire material but also on the sensitivity to stresses due to breaks, grooves, and marks of the fretting (vibration fatigue caused by small relative shift of individual wires in the multiwire threads and contact between the conductor and hanging clamp) [2]. In the case of submarine power cables, the main causes of failure are the loss of isolating covers because of abrasion due to currents and seabed unevenness and corrosion of the conductive parts of the cables [4]. For underground cables, isolation failure occurs due to the impact of heavy metals contained in the soil [5]. At nuclear power plants, power cable degradation is observed due to exposure to ionizing radiation [7].

Testing and diagnostics of the status of the conductive and isolating parts of power cables are the primary tasks in the electrical-network operation. Most of the related publications are devoted to techniques which are phenomenological and work with macroscopic parameters that can be measured in an experiment on a whole cable or an entire cable thread. Among them, for example, there are measurement of electrical resistance [2-4,10], superheterodyne ultrasonic listening [1,11], measurement of residual voltage [7], and traveling wave methods [12].

However, the accumulation of defects in the crystal structure and formation of cracks in the surface layers of the wire metal when exposed to a tensile load and to the environment during operation [13] should lead to a change in the structural, microstructural, and related physical properties of single wires of multi-wire strands of a power cable at the micro level $[3,14,15]$. The study of structural, microstructural, and acoustic characteristics allows one to control the wire-material quality of the cables, as well as to study microprocesses that can proceed when the external load, temperature, etc. change. Therefore, determining dependence of structural, microstructural, and elastoplastic properties of individual wires of the cable multi-wire strands on the service life, which are due to accumulation of fatigue damage in the wire material of the cables, will allow for the monitoring of the technical state of the power cables.

Thus, experimental studies of the ongoing changes in the structure, microstructure, and elastoplastic properties of wires during operation provide information allowing for the estimation of the residual life and the diagnosis of the technical state of wires.

There are a limited number of articles in peer-reviewed journals in the literature, where the results of the study of the structure and microstructure of cables from existing power transmission lines are presented.

In [16], the results of a study of aluminum cables with a steel core (Aluminum Conductor Steel Reinforced (ACSR, explanation of all abbreviations and the nomenclature used is given in the end of the article)) are presented after forty years of service in the industrial atmosphere of the Czech Republic. Methods of optical microscopy, scanning electron microscopy (SEM), and energy-dispersive X-ray spectroscopy (EDX or ESD) were used. With the help of EDS, an increased sulfur content was determined ( $\sim \mathrm{wt} . \%)$ in outer wires, which presumably comes from $\mathrm{SO}_{2}$ in the air atmosphere and is a corrosion catalyst. Using OM and SEM, the thickness of the near-surface corrosion layer is determined, which on average ranges from $\sim 20 \mu \mathrm{m}$ to $\sim 100 \mu \mathrm{m}$ and up to a maximum value from $\sim 50 \mu \mathrm{m}$ to $\sim 500 \mu \mathrm{m}$, depending on the position of the wire in the cable. It was found that the average corrosion rate is $\sim 1 \mu \mathrm{m} /$ year, and the maximum is up to $\sim 5 \mu \mathrm{m} /$ year. The XRD method showed that alumina $\left(\alpha-\mathrm{Al}_{2} \mathrm{O}_{3}\right)$ and low quartz $\left(\alpha-\mathrm{SiO}_{2}\right)$ crystallize in the near-surface corrosion layers, as can be concluded by the observation of weak reflections of the corresponding phases on the XRD pattern.

The ACSR cable of the overhead power-transmission line with the service life of 29 years crossing the Parana River (Brasil) was investigated in [17] after break failure. By means of EDS, OM, and SEM it is found that fretting produced the hard aluminum oxide and oxidized silicon particles, which acted as abrasive material against comparatively soft $\mathrm{Al}$ wire material leading to breakage. Using EDS, OM, and SEM methods, it was found that fretting of the wires during the exploitation leads to formation of hard particles of 
aluminum oxide and oxidized silicon in the near-surface layers of the $\mathrm{Al}$ wires, which act as an abrasive material against the relatively soft Al-wire material, resulting in wire breakage.

It is also worth mentioning the study of the structure and microstructure of aluminum panels after exposure for 13-16 years in various areas of Spain [18]. The EDS and SEM methods show the development of corrosion near-surface layer in the panels with a depth of $\sim 20 \mu \mathrm{m}$ to $\sim 100 \mu \mathrm{m}$, depending on the type of atmosphere (rural, urban, industrial, marine). XRD phase analysis confirms the formation of crystalline bayerite, $\mathrm{Al}(\mathrm{OH})_{3}$, in the corrosion layers (no XRD pattern is presented). Apparently, the difference with [16], where aluminum and silicon oxides were detected, is due to different production technology of cables and panels, which leads to a different elemental composition of impurities in the $\mathrm{Al}$ material. Similar to [16], EDS found the presence of $\mathrm{S}$ for the panels exposed in the industrial and marine atmosphere ( $\mathrm{Cl}$ was detected additionally).

Thus, all these articles are devoted to the study of wires only after one value of the service life (or close service life values for panels) or after a break during operation. Of the quantitative methods, only EDS (EDX) is used; quantitative corrosion characteristics (rate of corrosion, thickness of the corrosion layer) are also evaluated by means of OM and SEM. Young's modulus is presented only in one work [2] for new Al wires of different impurity composition from the cables without steel core (named "All Aluminum Alloy Conductor" (AAAC)), close values of $E=68.9 \mathrm{GPa}$ and $69.0 \mathrm{GPa}$ were obtained. XRD was used only qualitatively for X-ray phase analysis.

In contrast to the investigations discussed above, the present study examines a set of AAAC wires of the existing overhead power-transmission lines with a different service life from 0 (new) to 62 years. Quantitative methods of XRD and electron backscattering diffraction (EBSD), as well as the method of densitometry, were used to study the structural and microstructural parameters of wires.

Changes in microplastic characteristics of wires depending on their service life are also investigated. The current understanding of dislocations which gives the satisfactory description of mechanical and acoustical properties of single crystals and coarse-grained polycrystals arose long ago $[19,20]$, having been developed for more than eighty years. At the same time, a number of publications, e.g., References [21-23] are devoted to relations between acoustic (effective modulus of elasticity and absorption of energy of elastic vibrations or internal friction) and mechanical (plasticity, hardness) properties.

Here, we study the characteristics of elastic and reversible microplastic deformations (the Young's (elastic) modulus $E$, amplitude-independent decrement $\delta_{i}$, microplastic flow stress $\sigma_{s}$ ), associated with the vibrational motion of dislocations. Both the structure (unit cell parameters and corresponding calculated X-ray mass density as well as preferred crystallographic orientation characteristics) and microstructure (sizes of the X-ray coherent scattering areas (CSAs, the term 'crystallites' is also used) and absolute values of average microstrains in them) have been studied by means of the XRD technique. The sizes of the grains and their preferred orientation were studied by means of the EBSD technique. Besides, to control the elemental composition, the samples were investigated by means of the SEM and EDX techniques, while densitometric measurements were carried out to determine the sample mass densities.

\section{Materials and Methods}

\subsection{Samples}

To determine the sample parameters which change within the exploitation time, sections of wires of overhead power-transmission lines (rated voltage of $0.45 \mathrm{kV}$ ) with different periods of operation from 0 (new/fresh) up to 62 years in atmospheric conditions of the Volgograd region of Russia were selected for research (see Table 1). All wire samples were cut off from the outer wires of the operated cables after replacing the existing overhead power lines. The section lengths were $\sim 1$ to $\sim 3 \mathrm{~m}$. All the wires except for the N3 one had been exploited without any damage. The N3 wire was exploited for 35 years, whereupon a 
cutoff and short circuit to the ground had happened. Thereafter, the wire was under the high voltage during 1.5 to $2 \mathrm{~h}$ and was partly (20 to $30 \%$ ) burned.

The cables under study are single aluminum multi-wire strands without isolation. The samples should nominally be the same, and since they were manufactured according to the same state standards, there were no changes in the manufacturing technology and design of wires during the analyzed time period. Technical characteristics according to the cable-maker's data sheet are as follows: the cross section of the multi-wire thread of the cable is $49.5 \mathrm{~mm}^{2}$, and the rated mass of the cable is $135 \mathrm{~g} / \mathrm{m}$. The wire material except Al may contain up to $0.40 \mathrm{wt} . \% \mathrm{Si}, 0.35 \mathrm{wt} . \% \mathrm{Fe}$, and $0.45 \mathrm{wt} . \% \mathrm{Mg}$. The multi-wire strand of the cable is twisted from 6 single $\mathrm{Al}$ conducting wires with a nominal diameter of $3 \mathrm{~mm}$ (in the following text these cables/wires will be called A50 type cables/wires). The inspection of wires with optical microscope revealed that the actual diameters of the wire threads vary from 2.8 to $3.2 \mathrm{~mm}$. Besides, a fresh cable (0 years of operation) was also investigated, hereinafter referred to as AC 50 type, which is characterized by the same technical characteristics as the A50 cable. The only special feature being the cable composition, namely the AC50 multi-wire strand contains $5 \mathrm{Al}$ single wires wrapped around a steel core, the $\mathrm{Al}$ wires and core having the same nominal $3 \mathrm{~mm}$ diameter. The A50 and AC50 cables are types of the AAAC and ACSR cables studied in the literature $[2,14,16,17]$.

Table 1. Samples of overhead power-transmission-line wires, which were selected for research.

\begin{tabular}{|c|c|c|c|c|}
\hline $\begin{array}{c}\text { Sample } \\
N\end{array}$ & Type & $\begin{array}{c}\text { Service } \\
\text { Life, } \\
\text { Years }\end{array}$ & Damage & Remark \\
\hline $5-2$ & \multirow{5}{*}{ A50 } & 0 & \multirow{4}{*}{ No damage } & \multirow{4}{*}{$\begin{array}{l}\text { Samples under study were cut } \\
\text { from one of the edges of sections with } \\
\text { a length of } \sim 1 \text { to } \sim 3 \mathrm{~m}\end{array}$} \\
\hline 8 & & 10 & & \\
\hline 7 & & 18 & & \\
\hline $6-2$ & & 62 & & \\
\hline 3 & & 35 & $\begin{array}{l}\text { Cutoff and short circuit } \\
\text { to the ground. After the } \\
\text { cutoff the wire was under } \\
\text { the high voltage during } \\
1.5 \text { to } 2 \mathrm{~h} \text { and was } \\
\text { partly burned }\end{array}$ & $\begin{array}{l}\text { Section length was } 3.2 \mathrm{~m} \text {; } \\
\text { the sample was cut from the } \\
\text { undamaged part in the middle }\end{array}$ \\
\hline 5 & AC50 & 0 & No damage & $\begin{array}{l}\text { Sample under study was cut from } \\
\text { one of the edges of the section with } \\
\text { a length of } \sim 1.3 \mathrm{~m}\end{array}$ \\
\hline
\end{tabular}

Samples in the form of cylindrical rods of single $\mathrm{Al}$ wire of the required length, namely $\sim 20 \mathrm{~mm}$ in the EDX, SEM, EBSD, and XRD measurements, $\sim 25 \mathrm{~mm}$ in acoustic studies, and $\sim 80 \mathrm{~mm}$ in densitometric measurements, were cut from undamaged part of lengthy sections (middle part of the damaged N3 wire, edges of the other wires). Thereafter, the samples were cleaned in an ultrasonic acetone bath.

It should be noted that deviations from technology of the wire producing cannot be excluded, especially during such a long period as 62 years. To take this possibility into account, research is currently underway on artificial fatigue tests of fresh samples. Aged samples will be examined by the same methods as natural ones in this article. Results will be compared and published later.

\subsection{SEM, EDX, and EBSD Experimental Details}

The studies of the surface, elemental composition, and grain structure were carried out using a scanning electron microscope (SEM) JSM 7001F (JEOL, Tokyo, Japan) equipped with an EDX INCA PentaFETx system (Abingdon-on-Thames, UK) and an HKL Nordlys 
EBSD detector (Oxford Instruments, Abingdon-on-Thames, UK). Setup of the EBSD measurements is shown in Supplementary Materials Figure S1a.

Two-stage sample preparation was employed. At the first step, both cross-cut and longitudinal sections of the wire samples were mechanically polished using the MultiPrep 8 set-up (Allied, San Francisco, CA, USA) with sequential reduction in the abrasive grains. At the second step, the polished surface was additionally smoothed with an argon-ion beam of the 1061 SEM Mill set-up (Fischione, Export, PA, USA).

\subsection{XRD Experimental Details}

The XRD studies allow one to control the phase composition of the samples, that is the presence of crystalline phases formed in the sample in an amount sufficient for detection of those phases by means of the XRD technique. Using the Bragg angles of the observed reflections and their Miller indices hkland upon introducing the necessary angle corrections, a powder XRD patterns allows one to obtain precise values of the parameters of unit cells of the phases detected. Besides, the reflection broadenings observed in XRD measurements makes it possible to determine the microstructure parameters, such as the sizes of the crystallites (CSAs) and microstrains in them.

XRD measurements have been carried out using a D2 Phaser powder diffractometer (Bruker AXS, Karlsruhe, Germany), built in the Bragg-Brentano geometry and employing the $\mathrm{Cu}-K_{\alpha 1,2}$ emission of an X-ray tube with a copper anode and a Ni $K_{\beta}$ filter as a monochromator. The scattered X-rays were collected by a linear position-sensitive semiconductor detector LYNXEYE (Bruker AXS) with the $5^{\circ}$ opening angle. XRD patterns were measured in the symmetrical $2 \theta-\theta$ scanning regime. To diminish possible effects of preferred crystallographic orientation, the samples were rotated around the sample holder axis, which coincided with the diffractometer goniometer axis. Setup of the XRD experiment is shown schematically in Supplementary Materials Figure S1b. The temperature inside the chamber, where the samples were placed, was kept equal to $314 \pm 1 \mathrm{~K}$. To avoid the diffraction contribution of the sample holder and the adhesive, the samples were mounted on a background-free holder in the form of the $\mathrm{Si}(119)$ single crystal wafer. To obtain the parameters of the observed XRD reflections (Bragg angle values $2 \theta_{\text {obs }}$, full width at half-maximum $(F W H M)$, maximum and integral intensities $\left(I_{\max }\right.$ and $I_{i n t}$, respectively), the measured XRD patterns were analyzed with the EVA program [24] upon introducing the necessary background and $\mathrm{Cu}-K_{\alpha 2}$-emission corrections utilizing the procedures of the same program. Both the phase analysis and assignment of the Miller hkl indices to observed reflections were accomplished using the Powder Diffraction File-2 (PDF-2) database [25] by means of EVA.

To determine angular corrections to the observed Bragg angles of reflections (namely $2 \Delta \theta_{z e r o}$, which is correcting shift of the zero of the counter, and $\Delta 2 \theta_{\text {displ }}$, which is displacement correction caused by misfit of the sample surface and diffractometer focal plane), additional measurements with reduced step time were carried out when samples were immersed in the $\mathrm{NaCl}$ powder, which was certificated by the XRD powder standard Si640d (NIST, Gaithersburg, MD, USA). The $\mathrm{NaCl}$ reflections were used as internal standards to determine both the $\Delta 2 \theta_{\text {zero }}$ and $\Delta 2 \theta_{\text {displ }}$ corrections from the XRD measurements of the sample with $\mathrm{NaCl}$ added. After the Bragg angle corrections, the very intense reflections of the sample from the same measurements with $\mathrm{NaCl}$ were used as external standards to determine the values of $\Delta 2 \theta_{\text {zero }}$ and $\Delta 2 \theta_{\text {displ }}$ of the final XRD measurements for the studied sample measured without $\mathrm{NaCl}$ under longer step time. The corrected values of the Bragg angles, that is $2 \theta=2 \theta_{o b s}+2 \Delta \theta_{z e r o}+2 \Delta \theta_{\text {displ }} \cos \theta_{o b s}$, were used in subsequent calculations.

The unit cell parameters were refined with the method of least squares using the Bragg angles $2 \theta$ of the reflections, which were angle corrected, employing the Celsiz program [26].

The microstructure parameters (average size of crystallites, $D$, as well as average magnitude of microstrains in them, $\varepsilon_{S}$ ) were calculated using the SizeCr program [27]. Here, the graphical methods of the Williamson-Hall plot (WHP) [28] and the size-strain plot (SSP) [29] were used in accordance with the procedures for pseudo-Voigt $(\mathrm{pV})$ re- 
flections [30] observed in the XRD patterns (to denote microstrains, the symbol $s$ is used in $[28,29])$.

To calculate the experimental points of the WHP and SSP graphs, in the Scherrer and Wilson-Stokes equations, which describe, respectively, the broadening of reflections due to the size of crystallites and microstrains, the coefficients $K_{\text {Scherrer }}=0.94$ [31] and $K_{\text {strain }}=4$ [32] were used. For both WHP and SSP, approximation linear dependencies $Y=A+B \cdot X$ were analyzed ( $X$ and $Y$ expressions for the methods are formulated in $[28,29])$. The intersections with the $X$ and $Y$ axes give the average size of crystallites, $D$, as well as absolute average magnitude of microstrains, $\varepsilon_{s}$. In the case of the $\mathrm{pV}$ reflections $\left(0.636<F W H M / B_{\text {int }}<0.939\right.$ [33], where $B_{\text {int }}=I_{\text {int }} / I_{\max }$ is integral width of a reflection), $D=K_{\text {Scherrer }} \cdot \lambda / A$ (here, $\lambda$ is the $\mathrm{Cu}-K_{\alpha 1}$ wavelength), $\varepsilon_{s}=B^{1 / 2} \cdot 100 \%$ for WHP [28] and $D=1 / B, \varepsilon_{s}=A^{1 / 2} \cdot 2 / K_{\text {strain }} \cdot 100 \%$ for SSP [29].

In the case of microstrain absence (zero microstrain), when $B \leq 0$ for the WHP and $A \leq 0$ for the SSP, the SizeCr program computes the crystallite size for each observed reflection with use of the Sherrer equation and calculates the average $D$ with use of the least-squares method. The values of the estimated standard deviations (e.s.d.s) of both $D$ and $\varepsilon_{s}$ parameters in both WHP and SSP are determined from the e.s.d.s of the $A$ and $B$ coefficients, representing how much the experimental points are scattered around linear graphs of WHP and SSP. The degree of scattering can be expressed through the determination coefficient, $R_{\text {cod }}$ (see definition in Supplementary Materials (SM) in [29]). The closer the experimental points are arranged around the linear dependency, the higher the $R_{c o d}$ value is, and thus the smaller the e.s.d.s of both $D$ and $\varepsilon_{s}$ parameters are. As a rule, the determination coefficient, $R_{\text {cod }}$ is notably higher in SSP, and hence the SSP method is more precise than the WHP one. Furthermore, in order to increase the accuracy of both methods, the bad data points with high deviation from the majority of experimental points were not taken into account. The number of such points was negligible, e.g., one for the N3 sample and two for the N8 one. Note that $D$ and $\varepsilon_{s}$ obtained in this way differ from the former values within the limits of their e.s.d.s, and all trends in the service time dependencies remain qualitatively unchanged.

It is also worth noting that samples prepared for the XRD measurements were not ground into powder. As a result, the calculated parameters of both the structure and microstructure mainly refer to near-surface layers, from which the diffracted X-ray signal comes, being weakened by a factor of $e \approx 2.72$ in comparison with the incident X-ray beam. The corresponding penetration depth $T_{p e n}$ for the used symmetrical $2 \theta-\theta$-scanning regime of the XRD method, can be estimated as

$$
T_{p e n}=\sin (\theta) /\left(2 \cdot \mu_{l} \cdot \rho\right),
$$

where $\theta, \mu_{l}$, and $\rho$ are half a diffraction angle $2 \theta$, the linear absorption coefficient, and density of a material under study, respectively. Using the values $\mu_{l} \approx 48.657 \mathrm{~cm}^{2} / \mathrm{g}$ (for $\left.\mathrm{Cu}-K_{\alpha}\right)$, and $\rho \approx 2.7 \mathrm{~g} / \mathrm{cm}^{3}$, which are well known for $\mathrm{Al}$, and the maximum experimental value of the diffraction angle of $2 \theta \approx 140^{\circ}$, one obtains $T_{\text {pen }} \approx 35.8 \mu \mathrm{m}$.

\subsection{Experimental Details of Acoustic and Densitometric Measurement}

The studies of elastoplastic properties were carried out using the acoustic-resonance method. The concept of this method is the piezoquartz stimulation of a standing longitudinal ultrasonic wave in the composite oscillator, the latter being combined of this piezoquartz and a sample under study. In experiments, three parameters are registered, namely the resonance frequency $f$, stimulating voltage, and current through the quartz at the moment of the resonance, i.e., when the current is characterized by a maximum value (just at the resonance frequency $f$ of the stimulating voltage). These parameters are sufficient to determine the decrement $\delta$, the resonant frequency $f$, the amplitude of the vibrational deformation $\varepsilon$, and the elastic modulus (Young's modulus) $E$ of the sample under study. The principal scheme of the acoustic-resonance measurements is shown in Supplementary Materials Figure S1c. Amplitude of the vibrational deformation $\varepsilon$ is 
proportional to the current through the quartz crystal, whereas decrement $\delta$ is proportional to the equivalent electrical resistance of the quartz crystal or the quartz-sample complex. When measuring $E$ and $\delta$, a broad range of $\varepsilon$ was employed, although only moderate $\varepsilon$ amplitudes were used to preserve the structure of dislocations in the samples under study. Thus, the density of dislocations was not changed after acoustic exposure [34].

Each sample was formed as a cylindrical $25 \mathrm{~mm}$ rod. The chosen length provided the longitudinal vibration resonant frequency $f$ near $100 \mathrm{kHz}$. The Young's modulus can be determined as

$$
E=4 \rho \cdot l^{2} \cdot f^{2},
$$

where $l$ and $\rho$ are the sample length and density, respectively. The relative standard deviation of the determination of the modulus of elasticity is $\delta E / E=4 \cdot 10^{-3}$.

The method used makes it possible to study not only ultrasonic absorption (inner friction) but also inelastic (microplastic) properties. The data on these properties are obtained when measuring the Young's modulus $E$ and decrement $\delta$ just in the broad range of $\varepsilon$ as mentioned above. The matter is that, at $\varepsilon$ large enough to induce non-linear amplitude-dependent absorption $\delta_{h}$ in the material, the Young's modulus is modified. The amplitude dependent changes in $\delta$ and $E$ can be described with the following equations:

$$
\begin{aligned}
\delta_{h} & =\delta-\delta_{i}, \\
(\Delta E / E)_{h} & =\left(E-E_{i}\right) / E_{i} .
\end{aligned}
$$

Here, $E_{i}$ and $\delta_{i}$ are measured at small amplitudes $\varepsilon$ when both $E$ and $\delta$ are yet independent of $\varepsilon$. The amplitude dependent change of the Young's modulus $(\Delta E / E)_{h}$ is named defect of the Young's modulus.

Acoustic measurements in a broad range of $\varepsilon$ amplitudes also allow one to evaluate microplastic properties in "stress - inelastic deformation" coordinates commonly accepted in mechanical testing, when the non-linear inelastic deformation $\varepsilon_{d}=\varepsilon \cdot(\Delta E / E)_{h}$ is plotted along the abscissa and the value of the oscillatory stress amplitude $\sigma=E \cdot \varepsilon$ is plotted along the ordinate.

The densities of the wire samples were measured by hydrostatic weighing using the analytic balance Shimadzu AUW 120D (Shimadzu Corporation, Kyoto, Japan) equipped with the SMK-301 attachment. The method of the hydrostatic weighing allows one to determine density $\rho_{d}$ of a sample (integral over the entire sample volume) with extremely high accuracy. For the studied $\mathrm{Al}$ wire samples ( $80 \mathrm{~mm}$ lengths, masses about $1.5 \mathrm{~g})$, the distilled water was used in the density measurements. The e.s.d. of the mass measurement was $\sim 1 \cdot 10^{-5} \mathrm{~g}$, and the relative error $\delta \rho_{d} / \rho_{d}$ of the density measurements did not exceed $1 \cdot 10^{-4}$.

\section{Results}

\subsection{SEM and EDX Results}

The SEM images of the polished surfaces showed the suitability of all samples for subsequent EBSD analysis. However, since these images give no additional useful information on the structure characterization, they are not presented in this paper.

Some examples of the measured EDX spectra from various samples are presented in Figure 1 and in Supplementary Materials Figure S2. As was expected according to the wire-maker's data sheet, the results of the EDX analysis proved the main element of the wires to be $\mathrm{Al}(\sim 99 \mathrm{wt} . \%)$ with small admixtures of Fe (0.26 to $0.6 \mathrm{wt} . \%), \mathrm{Si}(0.06$ to $0.16 \mathrm{wt} . \%)$, and $\mathrm{O}$, whose content in samples notably rises after their long service life (see Figure 1a,b). Besides, there are extraneous element peaks in the EDX spectra. One of them is certainly related to Ar, which apparently appears as a result of the argon ion beam polishing; another one corresponds to $\mathrm{Ni}$, probably from the microscope chamber walls. 


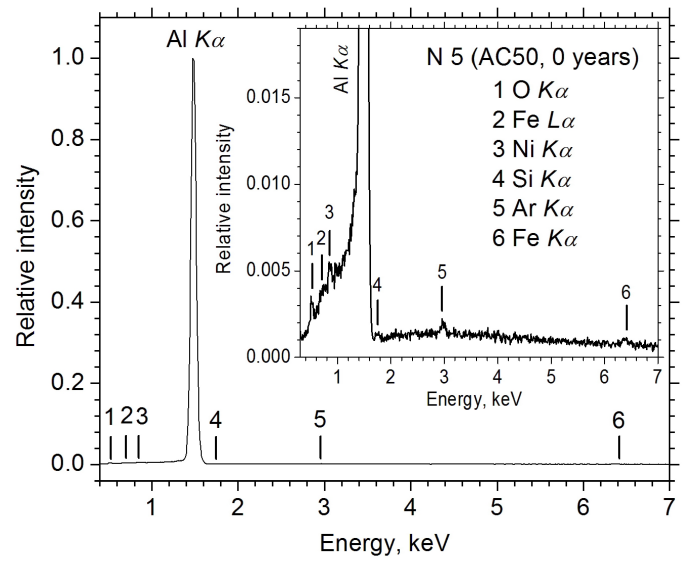

(a)

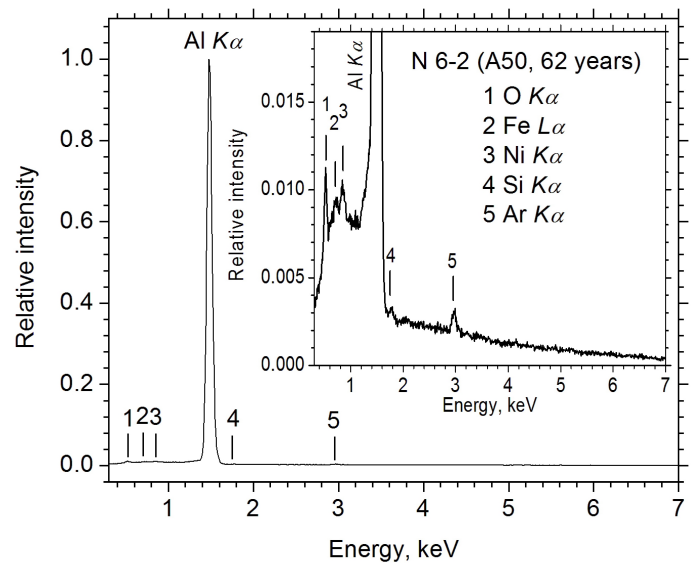

(b)

Figure 1. The EDX spectra of the samples (a) N5 (0 years) and (b) N6-2 (62 years).

\subsection{XRD Results}

Some examples of the measured XRD patterns are shown in Figure 2 (the rest are presented in the Supplementary Materials Figures S3 and S4). The observed splitting of the reflections is a result of use of the doublet X-ray line $\left(\mathrm{Cu}-K_{\alpha 1,2}\right)$. According to the phase analysis, all the intense reflections observed in the XRD patterns of all samples correspond to the $\mathrm{Al}$ cubic crystal (space group $F m \overline{3} m$ (225), $\alpha=4.04932 \AA$ at $298 \mathrm{~K}$ [35], the PDF-2 card 01-073-9843). All possible Al reflections are observed; therefore, the samples are polycrystalline. In samples with long operation period, a few (2 to 4$)$ very weak reflections are found, which can be attributed to the aluminum oxides, namely $\delta-\mathrm{Al}_{2} \mathrm{O}_{3}$ [36] (the PDF-2 card 00-056-1186) and/or $\delta^{*}-\mathrm{Al}_{2} \mathrm{O}_{3}$ [37] (the PDF-2 card 00-046-1215). Their observed and tabulated Bragg angle values are put in Supplementary Materials Table S1 and the tabulated Bragg angle positions are indicated with various symbols in Figure 2, Supplementary Materials Figures S3 and S4.

First of all, one has to pay attention to the trend in the change of the observed preferred orientation along the [011] direction, which rises with the increase in the wire service life. Indeed, Figure 3 and Table 2 show $I_{\max }^{022} / I_{\max }^{111}$, that is the ratio of maximum intensities of 022 and $111 \mathrm{Al}$ reflections depending on the service life and the corresponding tabulated value.

In the fresh sample, this ratio is already 1.75 times higher than the tabulated value, and the other ratios of intensities of the other reflections differ from the tabulated ones as well (compare, e.g., Figure 2a and inset of Figure 2c). When the service life increases, this ratio sharply increases almost fourfold up to 154(2) \% for the sample N7 (18 years in service), which implies the preferred orientation effect. When the service life increases further up to 62 years (the N6-2 sample), the preferred orientation remains practically unchanged (see Figure 3). Notably, the short circuit results in the ratio relaxation, so that the XRD pattern resembles the tabulated one where there is no the preferred orientation effect (compare Figure 2c and Inset of Figure 2c). In the fresh sample of the AC50 type the ratio $I_{\max }^{022} / I_{\max }^{111}$ is a bit higher than that in the fresh A50 type sample, and thus the preferred orientation effect is also a bit stronger. This is in contrast to the results in [16] (the only work found in which the measured XRD pattern is given), in which the Al wires from the ACSR cable of an overhead power line were investigated after 40 years of exploitation in the industrial atmosphere of the Czech Republic. For this cable, according to the published XRD pattern, the ratio of $I_{\max }^{022} / I_{\max }^{111} \approx 25.5 \%$ is close to the tabular value of $24.0 \%$. Probably, this difference is mainly due to the difference in the technology of preparing $\mathrm{Al}$ wires. This is supported by the fact that, unlike the wires in the present work, where the formation of $\delta$ - and /or $\delta^{*}-\mathrm{Al}_{2} \mathrm{O}_{3}$ is observed, the formation of weak reflections of alumina $\left(\alpha-\mathrm{Al}_{2} \mathrm{O}_{3}\right)$ and low quartz $\left(\mathrm{a}-\mathrm{SiO}_{2}\right)$ is noted in [16]. 


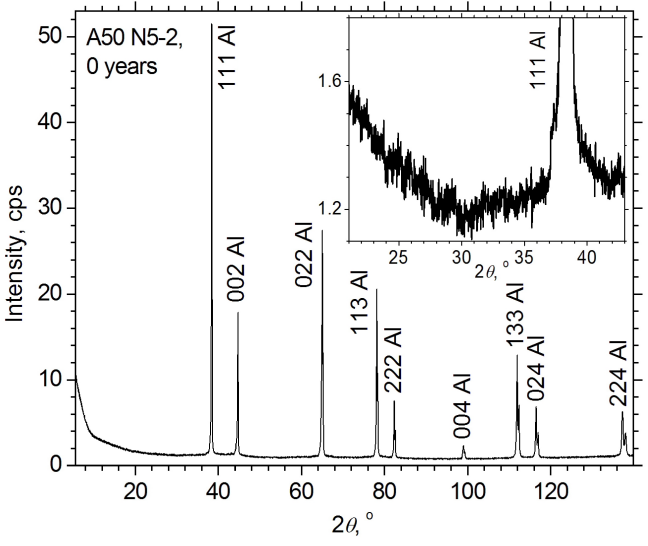

(a)

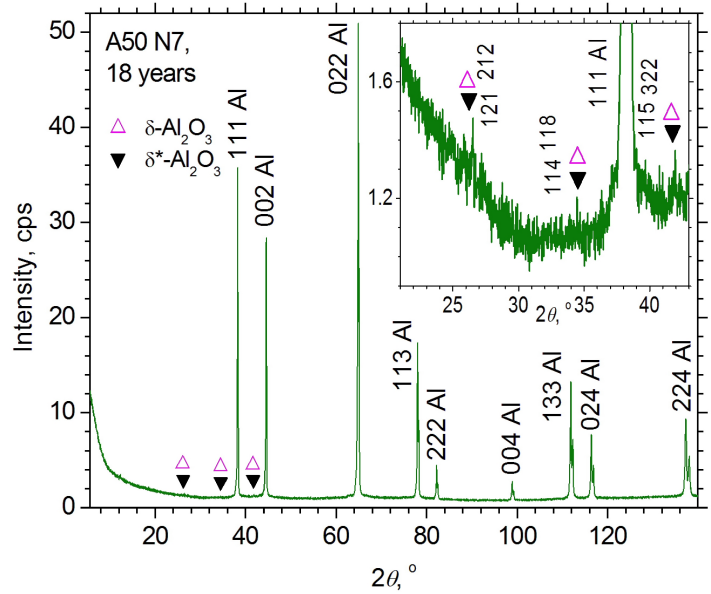

(b)

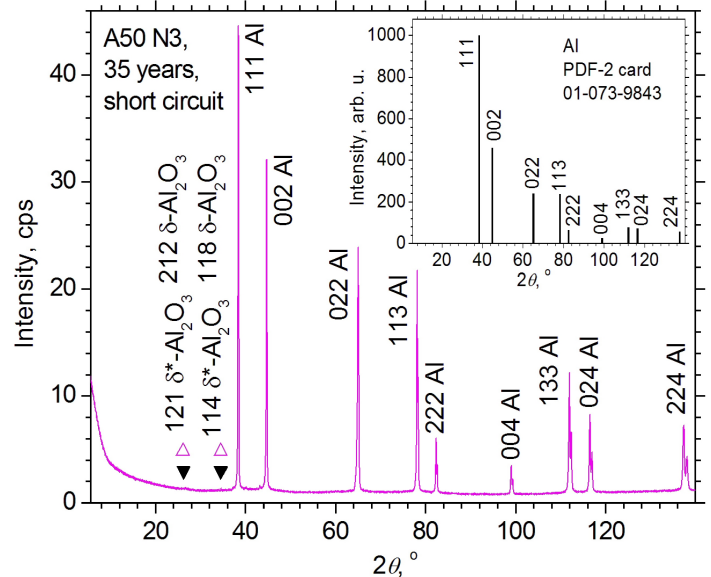

(c)

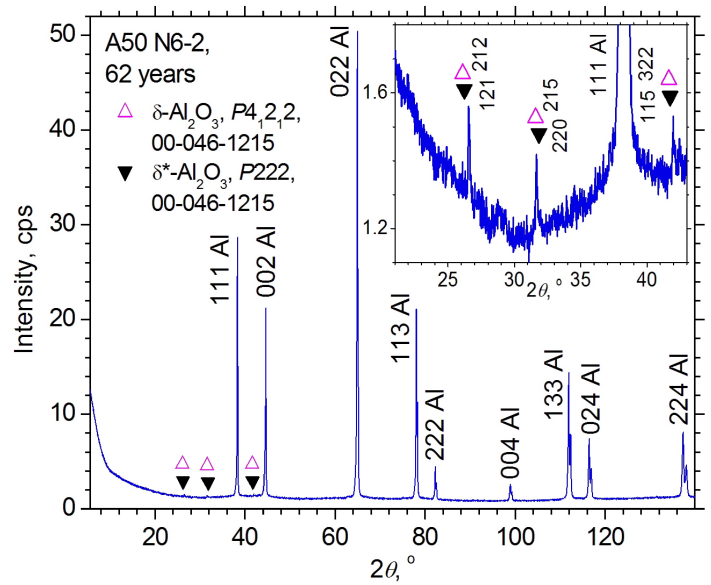

(d)

Figure 2. XRD patterns of samples N5-2 (a), N7 (b), N3 (c), and N6-2 (d). The Miller indices hkl attributed to Al are indicated as well as the service life of these samples. Insets $(\mathbf{a}, \mathbf{b}, \mathbf{d})$ show in detail the angle region $2 \theta=21^{\circ}-43^{\circ}$, where weak reflections attributed to the $\delta$ - and $\delta^{*}-\mathrm{Al}_{2} \mathrm{O}_{3}$ phases are formed (their space groups and numbers of the PDF- 2 cards are shown in the (d)). The Miller indices $h k l$ attributed to different $\mathrm{Al}_{2} \mathrm{O}_{3}$ crystalline phases are indicated with various symbols (see paper text). The bars with heights corresponding to the theoretical intensities of reflections in the inset (c) show the $\mathrm{Al}$ reflections according to the PDF-2 card.

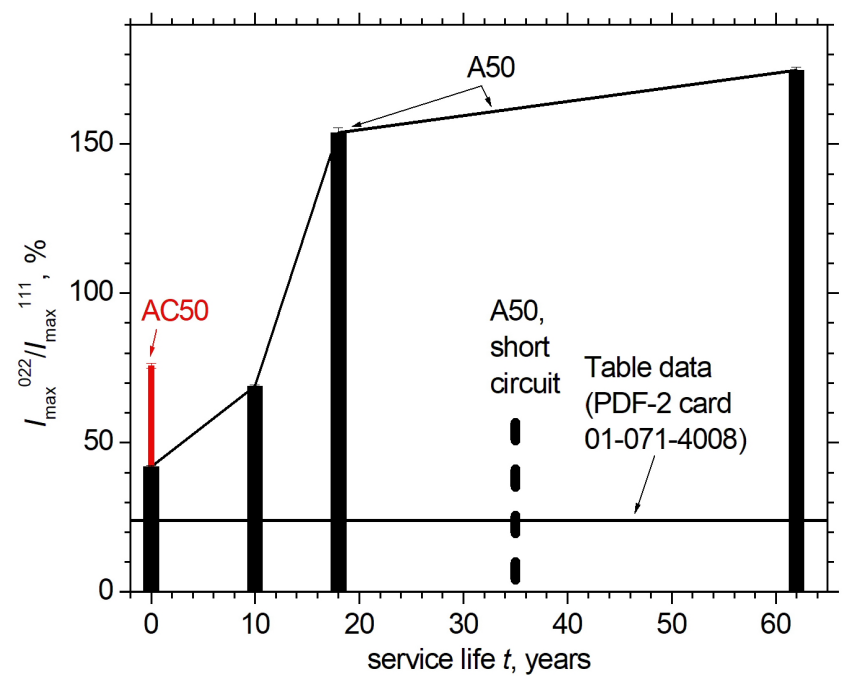

Figure 3. Dependency of the $I_{\max }^{022} / I_{\max }^{111}$ ratio on the service life of the Al wire samples. The line connecting experimental points is a guide to the eye only. 
Furthermore, the careful check-up of the measured XRD patterns reveals systematic shifts of reflections on the Bragg angle, which implies the change in the sample structures within the exploitation period. It is demonstrated by Figure 4, where the reflection with the Miller indices $h k l=133$ is taken as an example. When the exploitation period increases up to 18 years, the reflections shift to the smaller Bragg angles, whereas for the sample N3 (35 years of the exploitation followed by short circuit) they practically come back to the Bragg angle observed for the N5-2 sample (fresh).

Table 2. The XRD analysis results (samples were measured at the $T=314(1) \mathrm{K}$ ).

\begin{tabular}{|c|c|c|c|c|c|}
\hline & & $\begin{array}{c}\text { Observed Preferred } \\
\text { Orientation }\end{array}$ & & WHP & SSP \\
\hline Sample N/Years & {$[h k l]$} & $\begin{array}{l}I_{\max }^{022} / I_{\max }^{111}, \% \\
I_{\max }^{002} / I_{\max }^{022} \%\end{array}$ & $\begin{array}{c}a, \AA / \rho_{x}, \mathrm{~g} / \mathrm{cm}^{3} \\
D, \mathrm{~nm}\left(\text { Model } \varepsilon_{s}=0\right)\end{array}$ & $\begin{array}{c}D, \mathrm{~nm} \\
\varepsilon_{s}, \%\end{array}$ & $\begin{array}{c}D, \mathrm{~nm} \\
\varepsilon_{s}, \%\end{array}$ \\
\hline \multicolumn{6}{|c|}{ A50 type } \\
\hline $5-2 / 0$ & [011] & $\begin{array}{l}42.0(3) \\
76.4(7)\end{array}$ & $\begin{array}{c}4.05026(12) / 2.6973(2) \\
109(16)\end{array}$ & $\begin{array}{c}111(14) \\
0.010(14)\end{array}$ & $\begin{array}{c}109(16) \\
0\end{array}$ \\
\hline $8 / 10$ & [011] & $\begin{array}{l}69.0(4) \\
66.1(4)\end{array}$ & $\begin{array}{c}4.0515(5) / 2.6949(11) \\
139(16)\end{array}$ & $\begin{array}{l}302(54) \\
0.031(2)\end{array}$ & $\begin{array}{l}298(26) \\
0.031(2)\end{array}$ \\
\hline $7 / 18$ & [011] & $\begin{array}{c}153.8(1.6) \\
55.6(6)\end{array}$ & $\begin{array}{c}4.0525(9) / 2.6927(17) \\
126(33)\end{array}$ & $\begin{array}{l}246(55) \\
0.033(3)\end{array}$ & $\begin{array}{l}252(32) \\
0.034(3)\end{array}$ \\
\hline $3 / 35^{a}$ & $\sim$ no & $\begin{array}{c}54.6(4) \\
141.6(1.5)\end{array}$ & $\begin{array}{c}4.0507(2) / 2.6965(5) \\
96(11)\end{array}$ & $\begin{array}{l}112(11) \\
0.021(5)\end{array}$ & $\begin{array}{c}118(6) \\
0.025(5)\end{array}$ \\
\hline $6-2 / 62$ & [011] & $\begin{array}{c}174.7(1.1) \\
42.9(3)\end{array}$ & $\begin{array}{c}4.0513(6) / 2.6952(11) \\
128(34)\end{array}$ & $\begin{array}{l}222(69) \\
0.031(5)\end{array}$ & $\begin{array}{l}249(49) \\
0.033(4)\end{array}$ \\
\hline \multicolumn{6}{|c|}{ AC50 type } \\
\hline $5 / 0$ & [011] & $\begin{array}{l}75.8(9) \\
68.4(9)\end{array}$ & $\begin{array}{c}4.05032(10) / 2.6972(2) \\
138(16)\end{array}$ & $\begin{array}{c}141(17) \\
0.007(11)\end{array}$ & $\begin{array}{c}138(16) \\
0\end{array}$ \\
\hline \multicolumn{6}{|c|}{ Table data } \\
\hline $\begin{array}{c}\text { PDF-2 card } \\
01-071-4008 \\
T=312.3 \mathrm{~K}\end{array}$ & no & - & $\begin{array}{c}4.050694 / 2.69642 \\
-\end{array}$ & - & - \\
\hline $\begin{array}{c}\text { PDF-2 card } \\
01-073-9843 \\
T=298 \mathrm{~K}\end{array}$ & no & $\begin{array}{c}24.0 \\
191.7\end{array}$ & $\begin{array}{c}4.04932(2) / 2.6992(4) \\
-\end{array}$ & - & - \\
\hline
\end{tabular}

${ }^{a}$ after short circuit.

The Al cubic crystal unit cell parameter computed with the Celsiz program (leastsquares method) using the Bragg angles of all reflections observed are summarized in Table 2 and presented in Figure 5a, where the horizontal line indicates the tabulated value of the unit cell parameter $a=4.060694 \AA$ [38] according to the PDF-2 card 01-071-4008 at $T=312.3 \mathrm{~K}$, which is close to the temperature inside the chamber, where the samples were placed during measurements, $314 \pm 1 \mathrm{~K}$.

The fresh samples N5-2 and N5 (0 years, the A50 and AC50 types, respectively) have about same unit-cell parameter, $a=4.0503(1) \AA$, which is somewhat less than the parameter tabulated for an $\mathrm{Al}$ crystal. Apparently, this happens due to contamination of wires under study with small quantities of atoms of another sort (for example, $\mathrm{Si}$ and $\mathrm{Fe}$, whose Slater radius is $1.10 \AA$ and $1.40 \AA$, respectively, compared to $1.25 \AA$ for $\mathrm{Al}$ [39]). When the service life increases up to 18 years (the sample N7 of the A50 type), the $a$ parameter increases practically linearly, i.e., the $\mathrm{Al}$ cell volume increases as $a^{3}$. However, for the N6-2 sample (62 years old) the unit cell parameter $a$ drastically decreases down to the tabulated/fresh-wire value. In sum, the $a(t)$ dependency looks bell-like if a line connects the four experimental points for samples of the A50 type (see Figure 5a). 


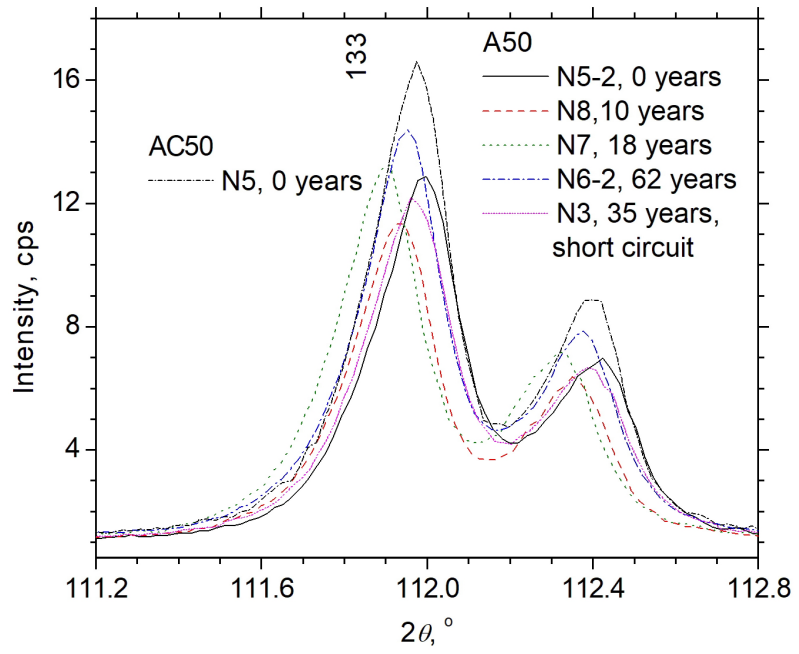

Figure 4. XRD pattern in the vicinity of the $h k l=133$ reflection for several samples.

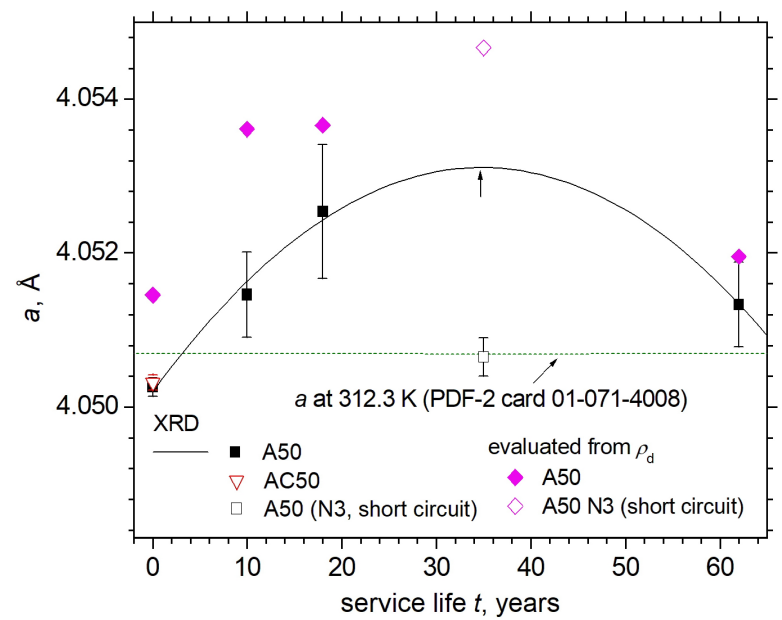

(a)

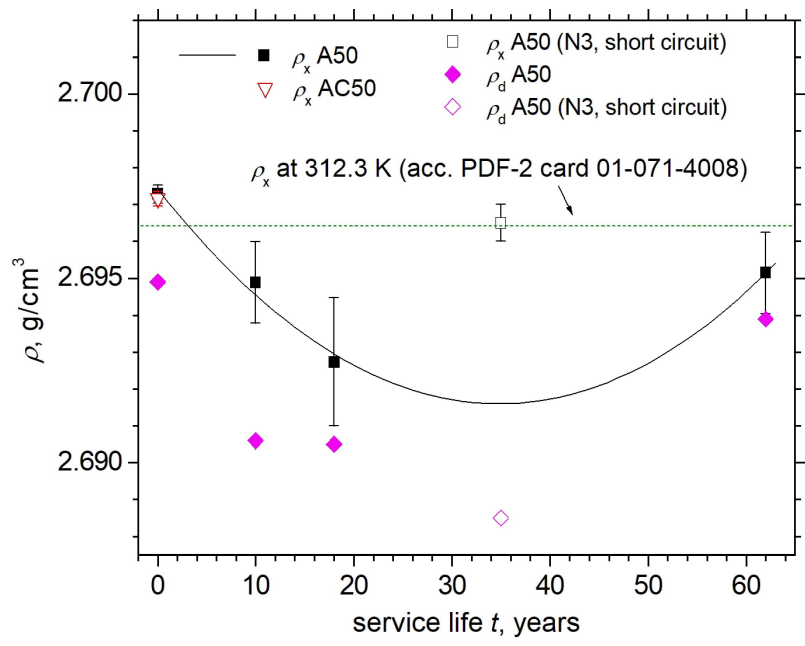

(b)

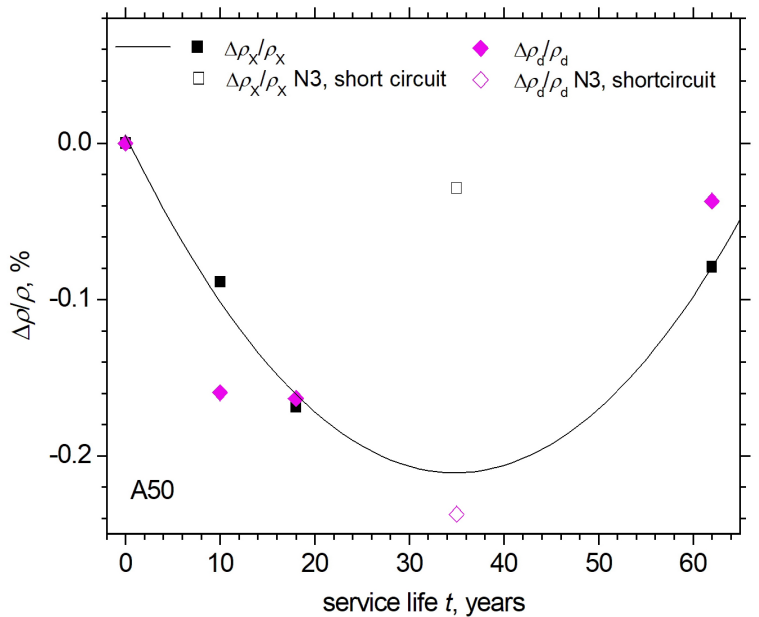

(c)

Figure 5. The dependencies of (a) the Al cubic crystal unit cell parameter $a$ and (b) densities $\rho_{x}$ computed from the XRD data and $\rho_{d}$ obtained in densitometric measurements as well as (c) the magnitude of the density defect (reduction of density) $\Delta \rho / \rho$ (where $\Delta \rho=\rho-\rho_{0 y e a r s}$ ) of the Al wires of overhead power transmission lines within their service life. The horizontal line in (a) indicates the tabulated $a$ value and that in (b) does it for the $\rho_{\text {table }}$ according to the PDF-2 card 01-071-4008. The parabolas are guides to the eye only. 
It is interesting to note that, in the N3 sample which underwent a short circuit, the unit cell parameter is also decreased down to the tabulated/fresh-wire value although the maximum of the parabolic approximation of the $a(t)$ dependency (the eye guide in Figure 5a) corresponds just to the value close to the service life of this sample N3 (35 years). Perhaps, here, the $\mathrm{Al}$ wire unit cell parameter $a$ is governed by the $\mathrm{Al}_{2} \mathrm{O}_{3}$ crystalline fraction. The fraction of the crystalline $\mathrm{Al}$ oxides formed over operation time is noticeably less than in sample N6-2, relaxing after a long service life of 62 years and less than in the sample N7 after 18 years operation (Figure 6). However, the insufficiency of experimental data does not allow for making extensive conclusions.

Figure 5 shows the X-ray average density of the samples, $\rho_{x}$, recalculated from the volume $V_{\text {cell }}$ of the $\mathrm{Al}$ unit cell and its mass (107.926 a.m.u.). In accordance with the inverse relationship between density and $V_{\text {cell }}, \rho_{x} \sim 1 / V_{\text {cell }}$, the $\rho_{x}(t)$ dependency shows opposite tendencies in comparison with $a(t)$. An increase in the cubic unit cell parameter $a$ with a service life of up to 18 years leads to a decrease in the average density of the material layer with a depth equal to the depth from which the XRD signal comes (for Al at the used radiation and diffraction angles, it is $\sim 36 \mu \mathrm{m}$, as estimated in Section 2.3 from the depth of penetration of X-rays). In other words, with a service life of up to 18 years, the density reduction of the near-surface $36 \mu \mathrm{m}$-deep layer occurs. The maximum absolute value of the density defect $\Delta \rho_{x} / \rho_{x} \approx 0.17 \%$ (Figure 5) observed from the experimental points for the studied A50 samples is reached after 18 years of service. However, after a short circuit (sample N 3) or a long service life (62 years, sample N 6-2), the density again increases to values in the fresh sample close to the tabulated value.

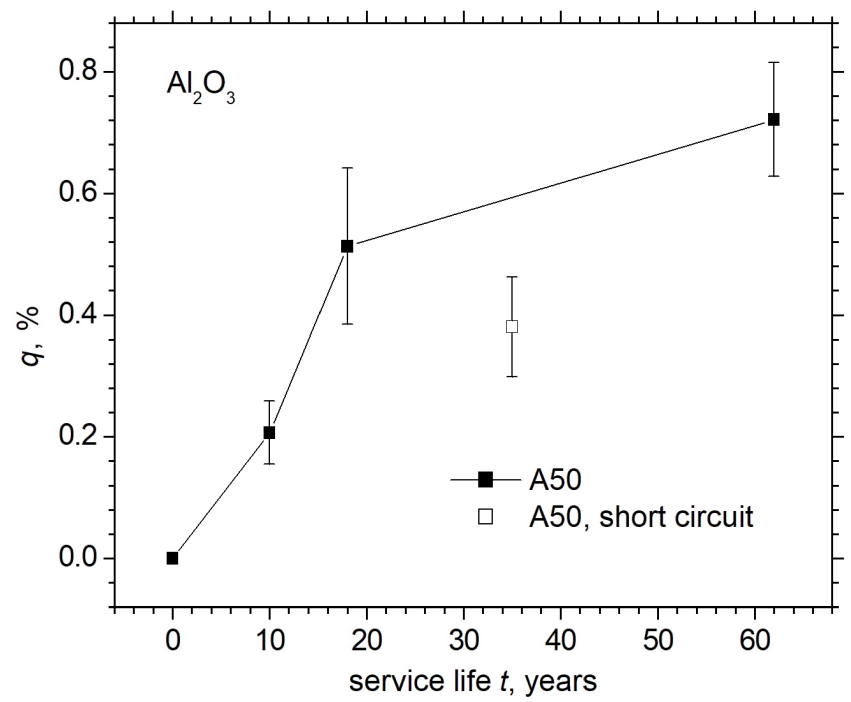

Figure 6. The volume fraction of the $\mathrm{Al}_{2} \mathrm{O}_{3}$ phases, which is estimated as $q=I_{\text {int }}^{A l_{2} \mathrm{O}_{3}} / I_{\text {int }}^{A l} \cdot 100 \%$ where $I_{\text {int }}^{\mathrm{Al}_{2} \mathrm{O}_{3}}$ is the integral intensity of the $121 \delta^{*}-\left(212 \delta\right.$-) $\mathrm{Al}_{2} \mathrm{O}_{3}$ reflection and $I_{\text {int }}^{A l}$ is the integral intensity of the strongest $\mathrm{Al}$ reflection.

It is possible that an increase in the average density of the near-surface layer of the samples is associated with the formation of a noticeable amount of $\delta$ - and $/$ or $\delta^{*}-\mathrm{Al}_{2} \mathrm{O}_{3}$, the density of which $\left(\sim 3.66 \mathrm{~g} / \mathrm{cm}^{3}\right)$ is significantly higher than that of $\mathrm{Al}\left(\sim 2.7 \mathrm{~g} / \mathrm{cm}^{3}\right)$. The number of reflections (see the inset in Figure $2 \mathrm{~d}$ in comparison with the insets in other Figures 2a,b and Supplementary Materials Figures S3 and S4) and their volume fraction (Figure 6) increases considerably.

Table 2 and Figure S6 in Supplementary Materials show the crystallite sizes $D$ obtained in the model without microstrains $\left(\varepsilon_{s}=0\right)$. In this model, with a wire service life of 10 years, the crystallite size grows weakly from 109(16) nm to 139(41) nm, then weakly decreases to $126(33) \mathrm{nm}$ and remains the same (128(34) $\mathrm{nm}$ ) for the sample with a service life of 62 years. A short circuit leads to a decrease in the size $D$ to a value of $96(11) \mathrm{nm}$, which is comparable with the fresh sample, similar to other parameters of this sample considered above. 
However, a thorough analysis of the XRD reflection profiles of the samples by the WHP and SSP methods (Supplementary Materials Figures S7 and S8) has shown that in most cases, with the possible exception of samples N5-2 and N5 without operation (where the effect is in the limit of e.s.d.), the broadening of reflections is caused not only by the crystallite size $D$ but also arises due to microdeformations $\varepsilon_{s}$ in them. The value of the $\mathrm{pV}$ type reflection criterion is very well preserved $\left(F W H M / B_{\text {int }}=0.80(6)-0.84(8)\right)$ regardless of the duration of operation of the wires up to 62 years and their type, A50 or AC50. As expected, in the case of SSP, the scattering of experimental points around the approximating linear graph is much less $\left(R_{\text {cod }}=89.53-99.01 \%\right)$ than in WHP $\left(R_{c o d}=1.72-92.78 \%\right)$. As a consequence, the mean values of $D$ and $\varepsilon_{S}$ obtained in the SSP are characterized by slightly lower standard deviations than those calculated using the WHP (Table 2). Figure 7 and Table 2 show a comparison of the average values of the crystallite size $D$ and the absolute average value of the microstrain $\varepsilon_{S}$ in them, obtained by means of SSP and WHP techniques. As one can see, both methods give comparable values that agree well within one e.s.d.

In the samples without operation, the crystallite sizes reach $D \approx 100 \mathrm{~nm}$ (A50 N5-2) and $140 \mathrm{~nm}$ (AC50 N5) comparable in limits of one-two e.s.d.s. $(\delta D \sim 10 \mathrm{~nm})$, and the microstrains in them are close to zero (Table 2 and Figure 7). The operating time dependency of $D$ is similar to that of the unit cell parameter $a$ (compare Figures $5 \mathrm{a}$ and $7 \mathrm{a}$ ), but the increase in the value of $D(t)$ (up to $\approx 300 \mathrm{~nm}$ ) occurs until the service life of $t=10$ years compared to $t=18$ years for $a(t)$. Then, with an increase in the service life to 18 years, the value of $D$ decreases slightly down to $D \approx 235 \mathrm{~nm}$ and remains at this value with an increase in the service life to 62 years. A short circuit causes $D$ to drop to values $D \approx 115 \mathrm{~nm}$ comparable to that in a fresh sample. The dependency of the average microstrain $\varepsilon_{s}$ on the service life repeats the dependency $D(t)$ but with a shift of the maximum to a value $\varepsilon_{s} \approx 0.034 \%$ between $t=10$ and 18 years, showing practically the same value after 62 years of service life ( $\varepsilon_{s} \approx 0.032 \%$, sample $\left.\mathrm{N} 6-2\right)$ and noticeable decrease $\left(\varepsilon_{s} \approx 0.023 \%\right.$ in sample $\left.\mathrm{N} 3\right)$ after short circuit.

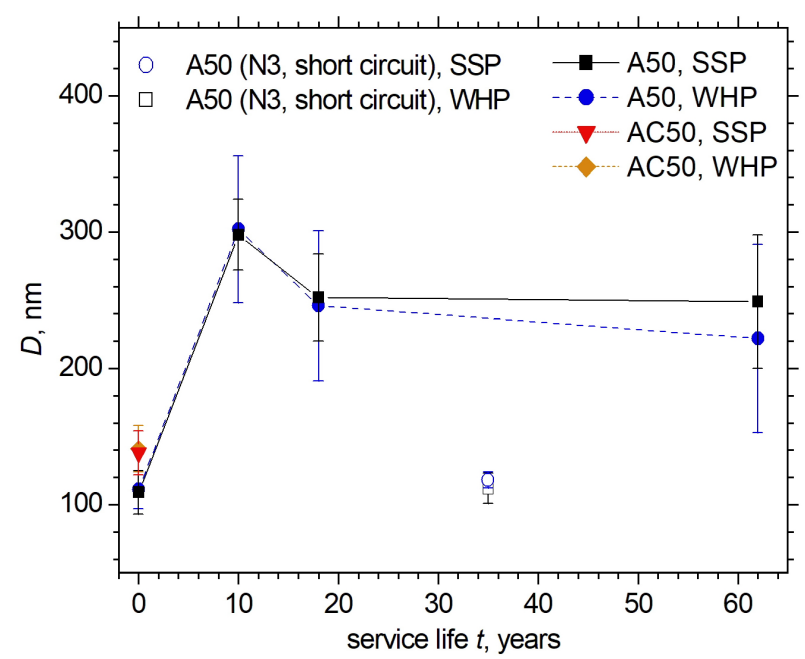

(a)

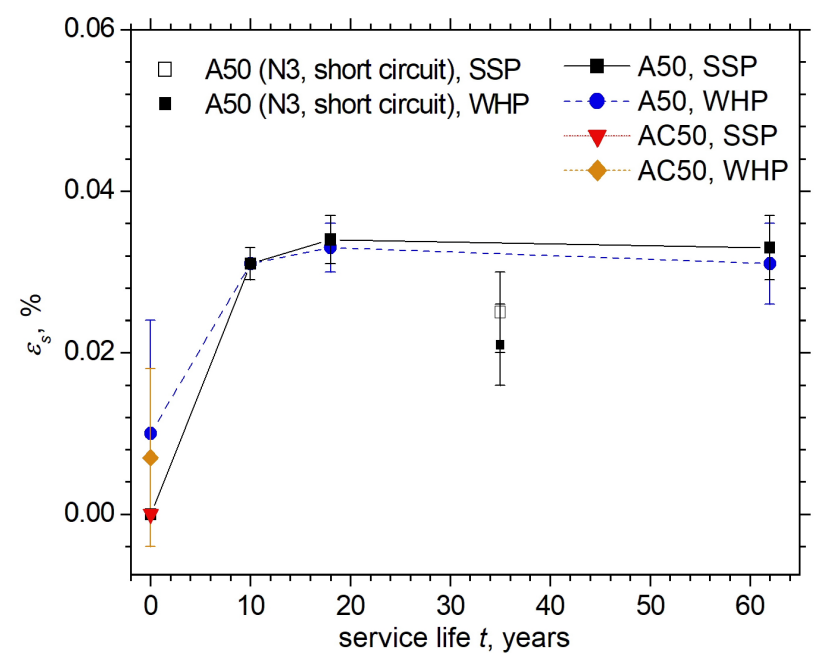

(b)

Figure 7. Operating time dependencies of the absolute average values of (a) the average crystallite sizes $D$ and (b) microstrain $\varepsilon_{S}$ of the Al material of the wires of overhead power lines, which were calculated by WHP and SSP methods. The lines are guides to the eye. 


\subsection{EBSD Results}

During the study by the EBSD method, the surface area of thin sections with a size of $100 \times 100 \mu \mathrm{m}^{2}$ with a step of $0.5 \mu \mathrm{m}$ was mapped. Figure 8a-e shows maps of the distribution of the Euler misorientation angles with superimposed grain boundaries for cross sections of specimens with different service life. Grain areas were considered to have the crystal structure, the misorientation inside which did not exceed $2^{\circ}$. Pixel color on maps corresponds to a combination of the Euler angles describing the orientation of the crystal lattice at a given point. As one can see, an increase in the sample service life leads to a rearrangement of the grain orientation of the cross sections. Figure $8 \mathrm{f}$ presents an example of a map for a longitudinal section of sample N5 (0 years). One can see that the grains on the longitudinal section have an elongated shape. Since the nature of the distribution of grain orientations of longitudinal thin sections is similar in samples of different service life, the further analysis was carried out only for thin sections of the cross section of the samples.

As a result of the analysis of the maps, the grain size distributions in the cross sections of the samples were drawn (Figure 9). One can see that, with an increase in the operating time, there is a decrease in the number of grains with a size of 1 to $3 \mu \mathrm{m}$ and the formation of grains with a size of 3.5 to $5 \mu \mathrm{m}$. Figure 10 shows the histograms of the distribution of aspect ratios of grains (ratios of the maximum grain size to the minimum) for samples of different service life, 0 to 62 years, which all have a similar form. The invariability of the aspect ratio shows that the shape of the grains does not change during operation and even after a short circuit (sample N3, 35 years of service). In addition, histograms of the distribution of the angle of misorientation of grain boundaries were built (Figure 11). In the fresh sample (N5, 0 years old), a high content of high-angle boundaries (misorientation greater than $15^{\circ}$ ) was noted, including those with misorientation in the range of $50^{\circ}-60^{\circ}$, i.e., the grains are misoriented rather uniformly, which indicates the absence of microcracks [40] in the fresh sample. With an increase in the service life, there is a decrease in the number of high-angle boundaries, and, accordingly, an increase in the number of low-angle boundaries (misorientation less than $15^{\circ}$ ), which, presumably, indicates a gradual alignment of grains along the general direction. According to [40], the formation of large ordered grain boundaries in nanocrystalline $\mathrm{Al}$ indicates the development of microcracks under tensile loading. The sample after a short circuit (N3, 35 years of service, Figure 11d) is qualitatively similar in this respect to other samples after some service life but without a short circuit.

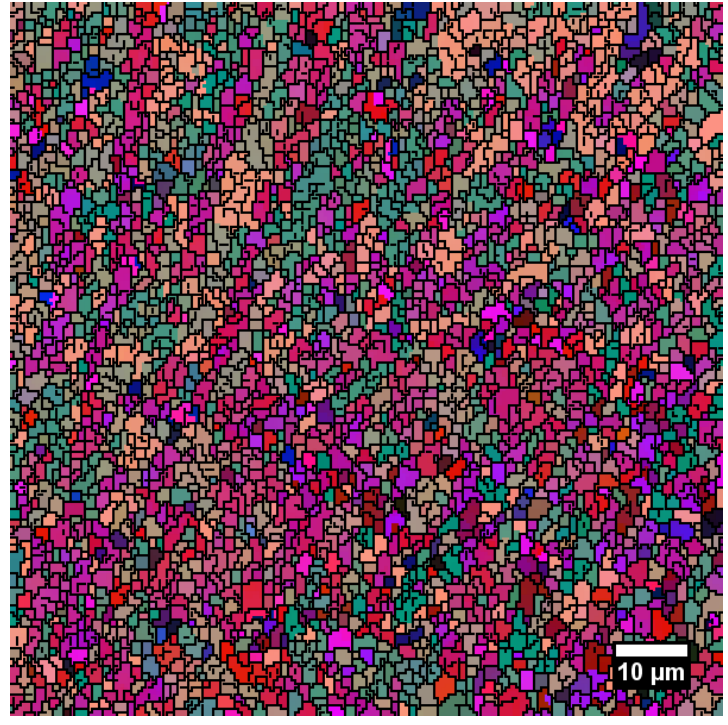

(a)

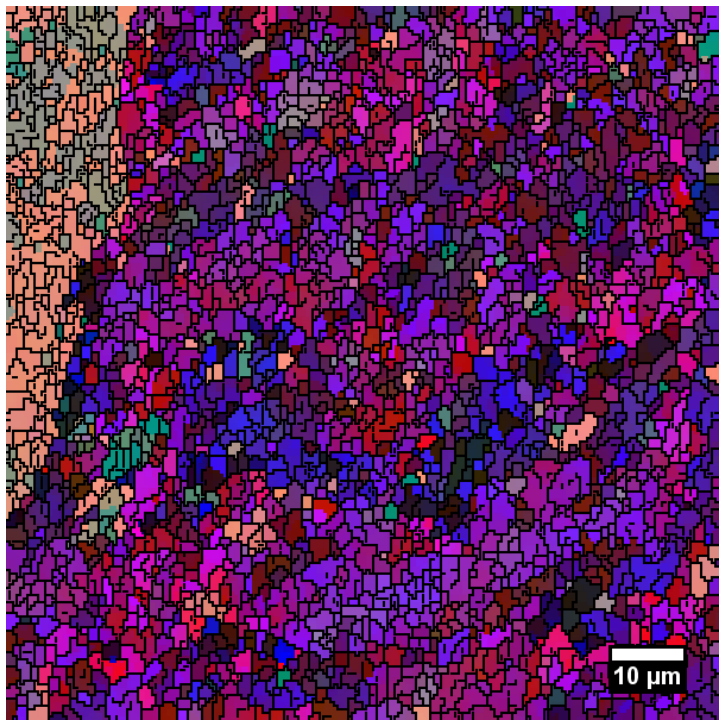

(d)

Figure 8. Cont. 


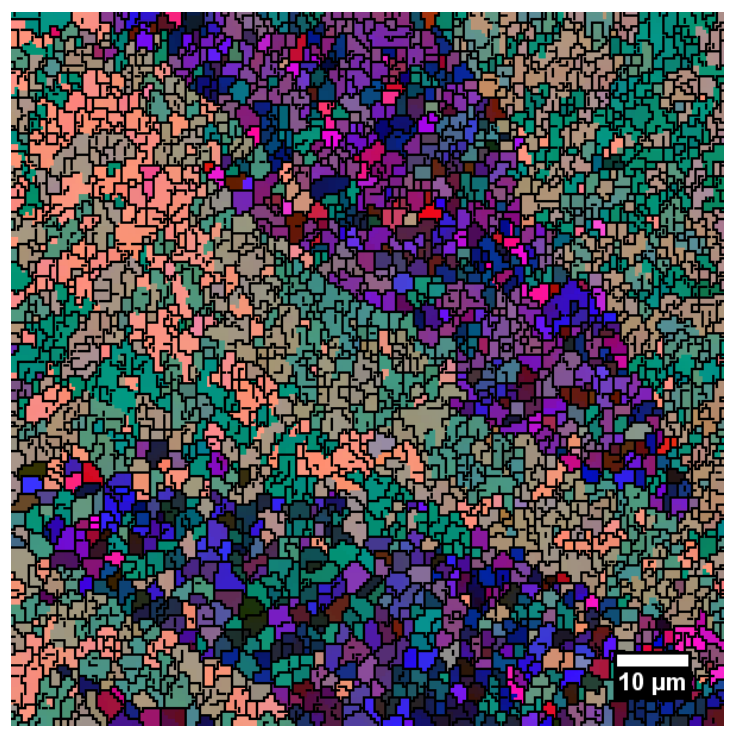

(b)

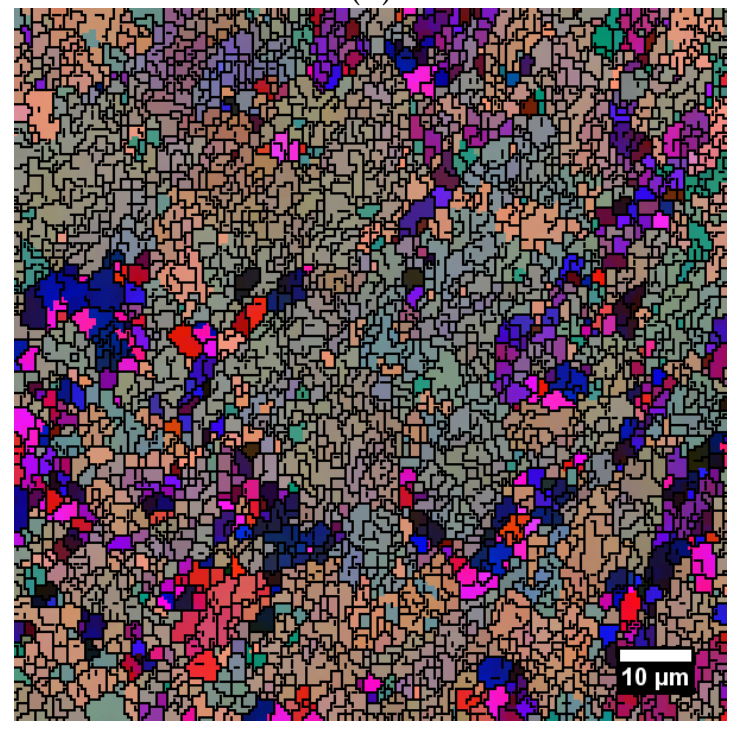

(c)

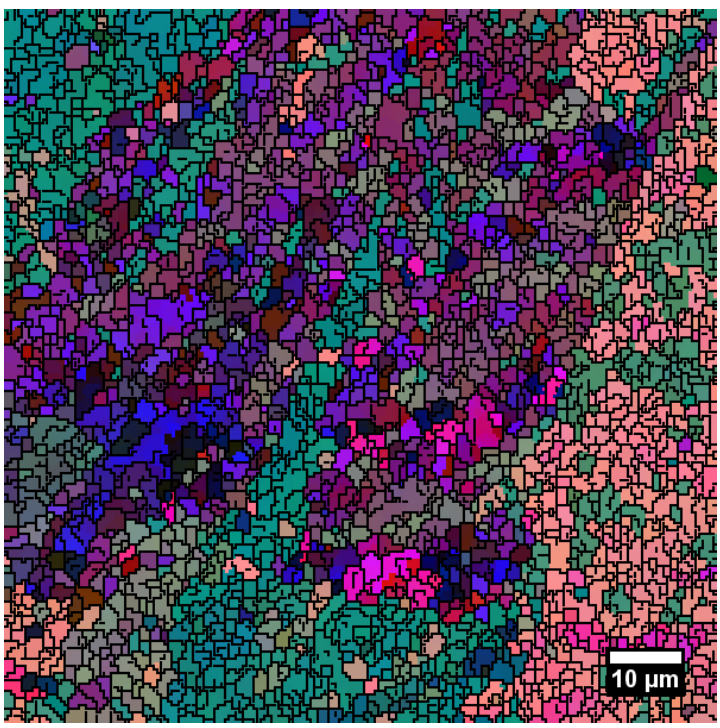

(e)

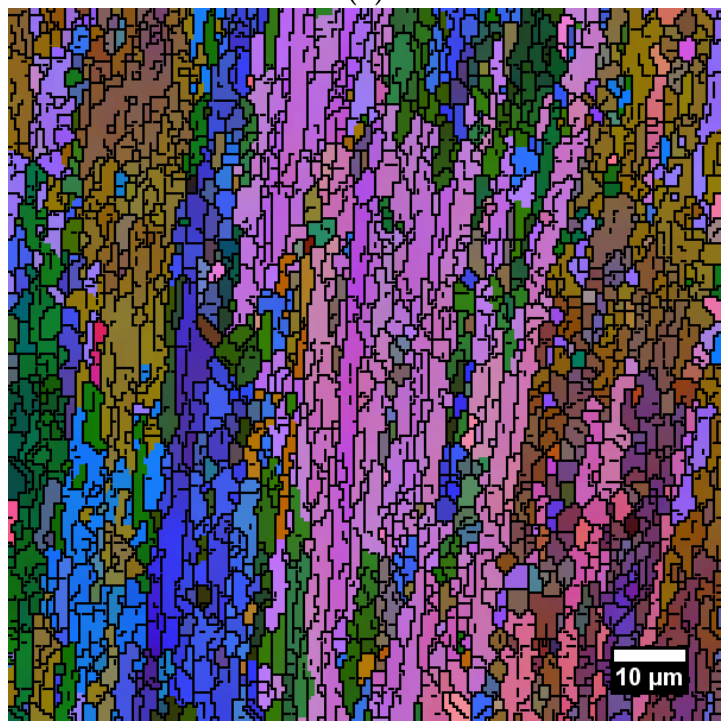

(f)

Figure 8. Maps of the distribution of the Euler misorientation angles for cross sections of samples with different service life: (a) N5 (0 years), (b) N8 (10 years), (c) N7 (18 years), (d) N3 (35 years and short circuit), (e) N6-2 (62 years), and (f) same N5 in longitudinal section. The grain boundaries are shown with solid thin lines. Each Euler angle corresponds to one of the RGB (Red-Green-Blue) image channels. 


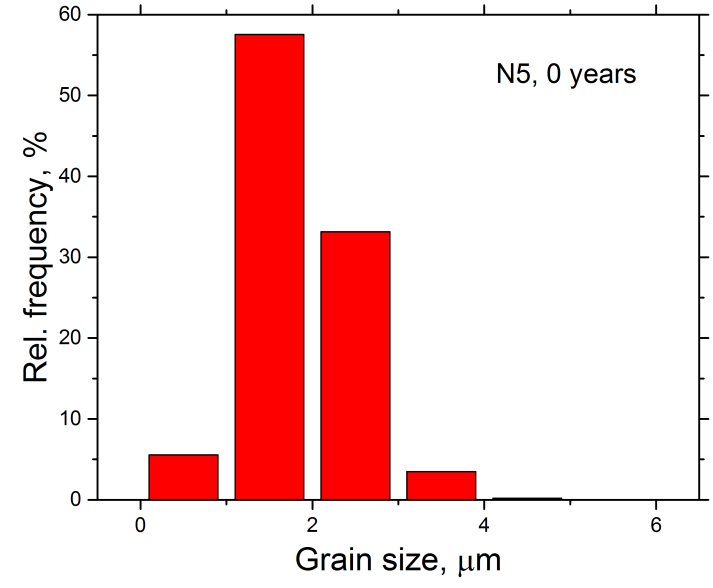

(a)

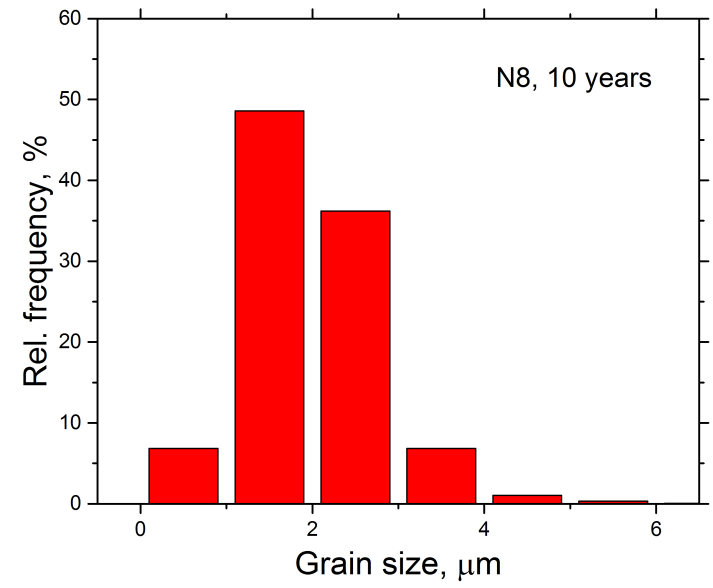

(b)

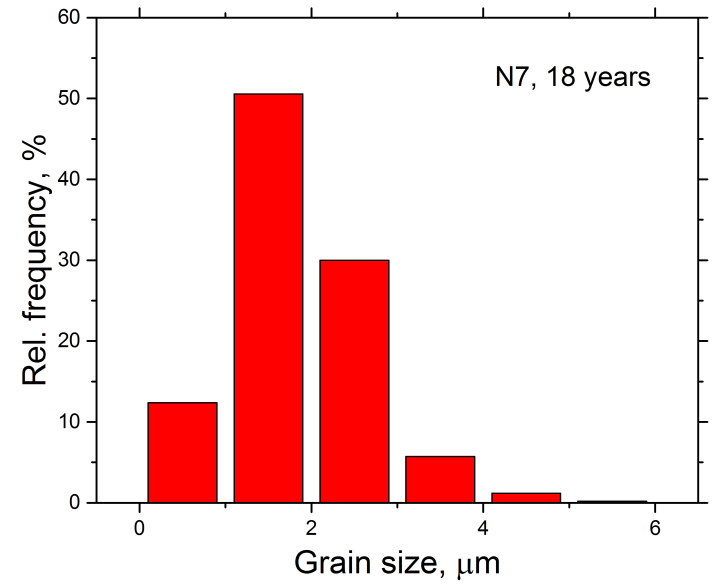

(c)

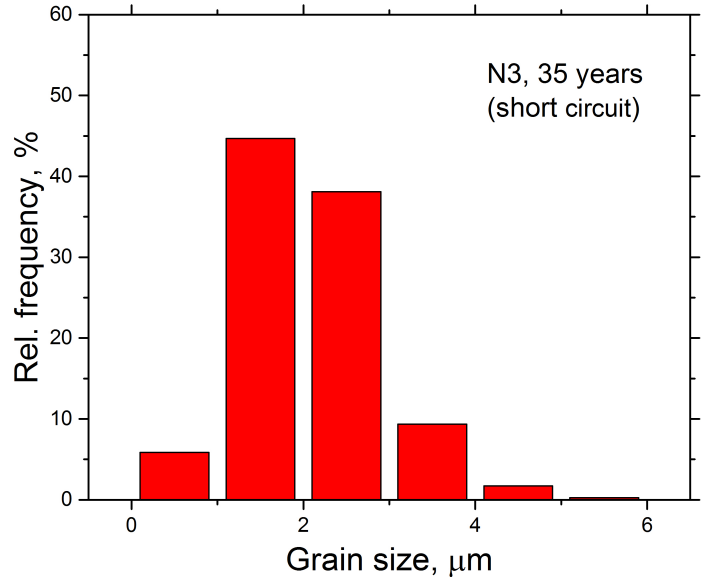

(d)

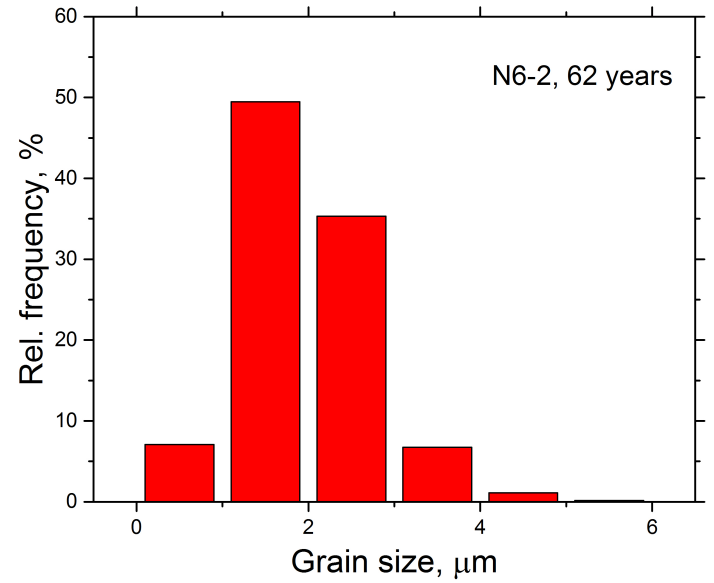

(e)

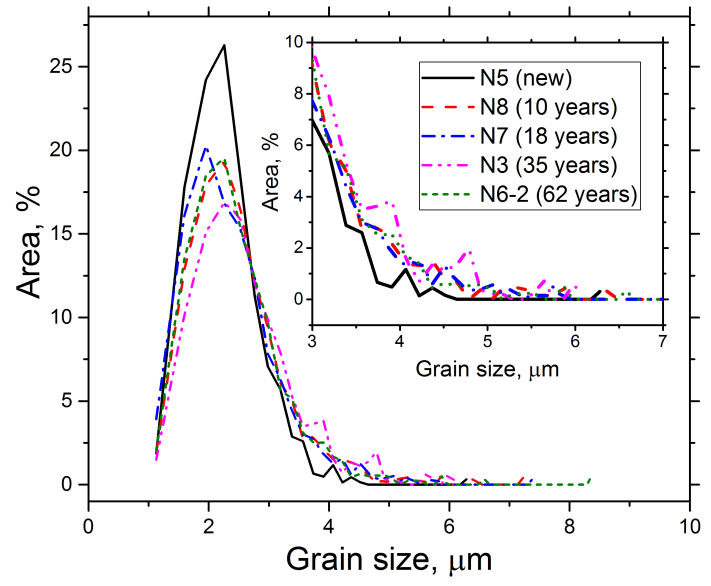

(f)

Figure 9. Histograms of grain size distribution for samples with different service life: (a) N5 (0 years), (b) N8 (10 years), (c) N7 (18 years), (d) N3 (35 years and short circuit), and (e) N6-2 (62 years). Panel (f) shows the dependency of the relative area occupied by grains vs. their size. 


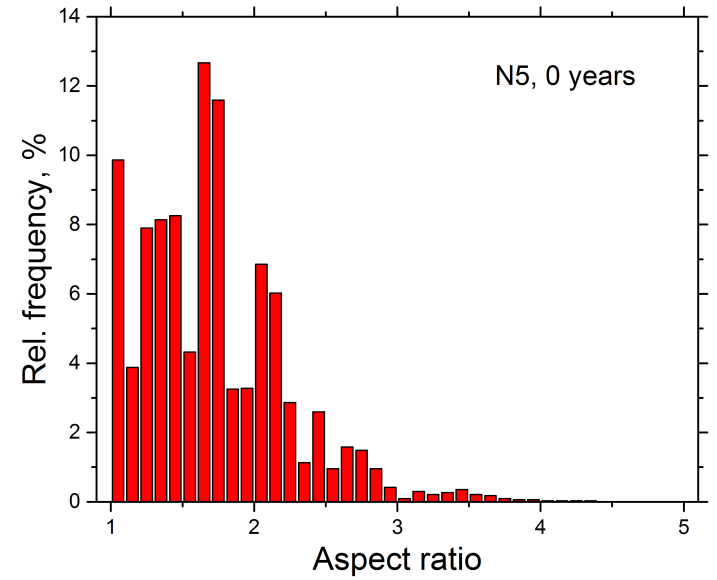

(a)

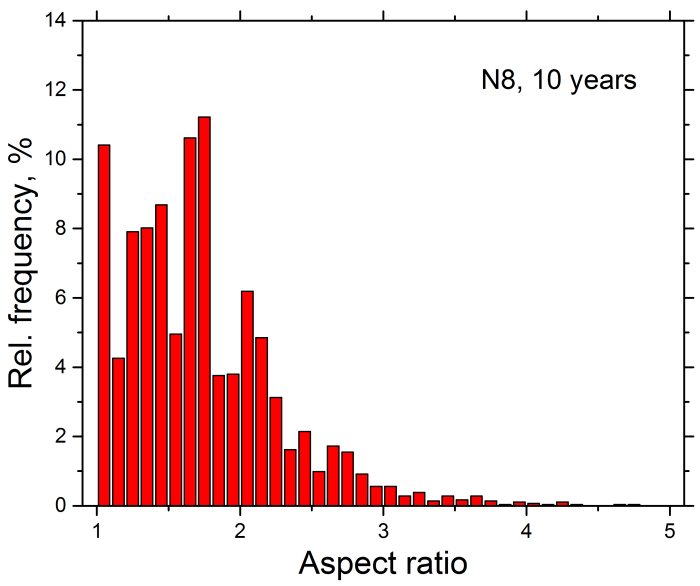

(b)

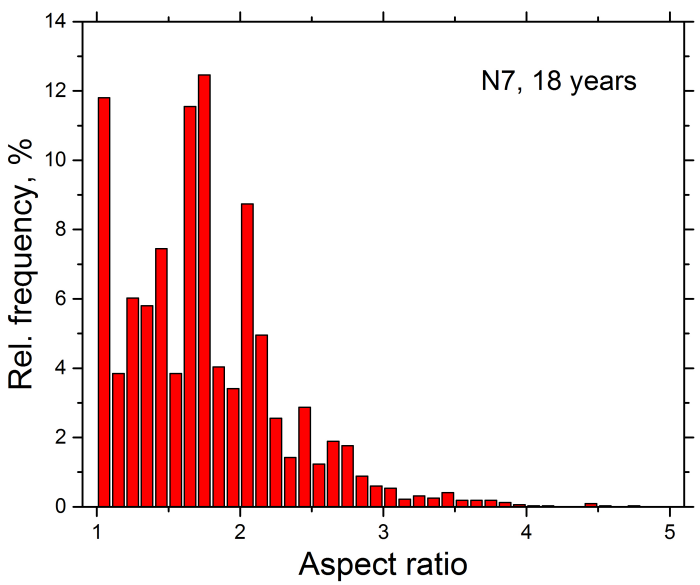

(c)

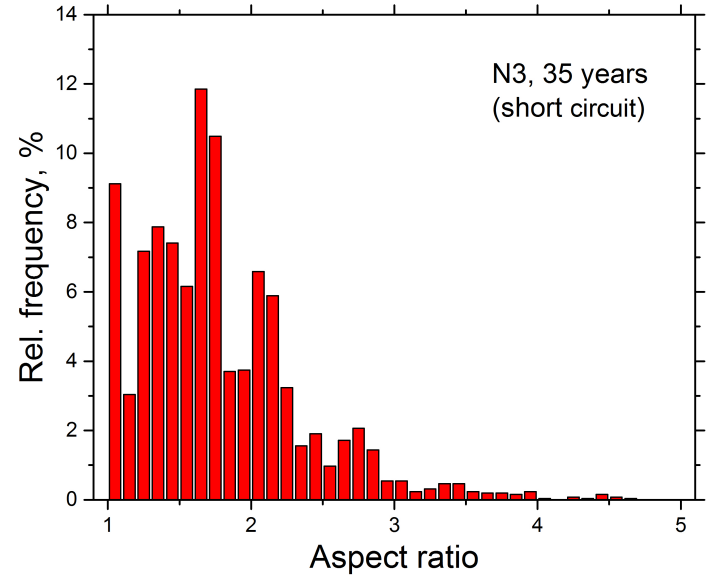

(d)

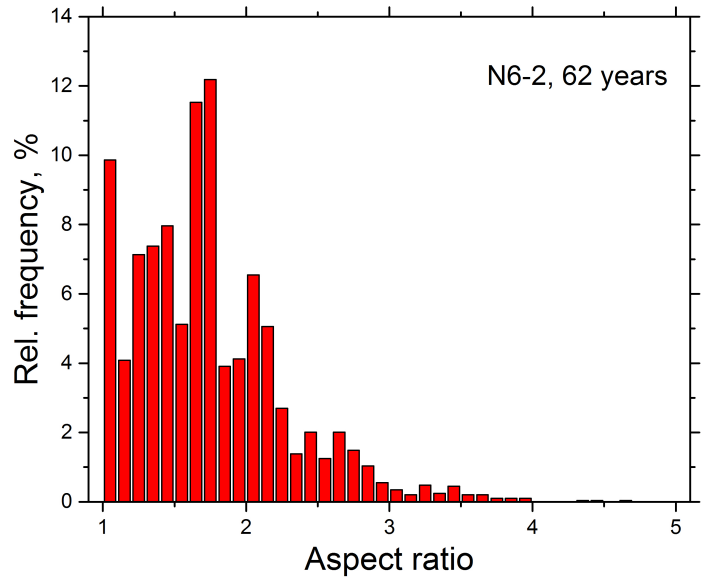

(e)

Figure 10. Histograms of grain aspect ratio distribution for samples with different service life: (a) N5 (0 years), (b) N8 (10 years), (c) N7 (18 years), (d) N3 (35 years and short circuit), and (e) N6-2 (62 years). 


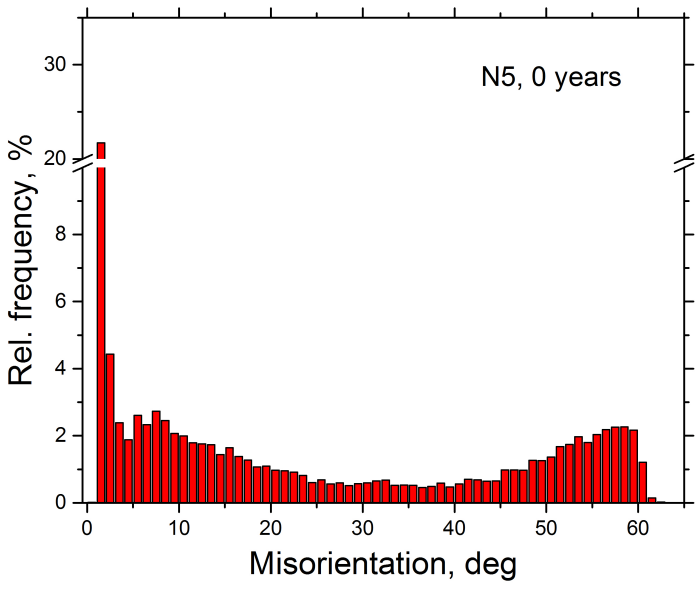

(a)

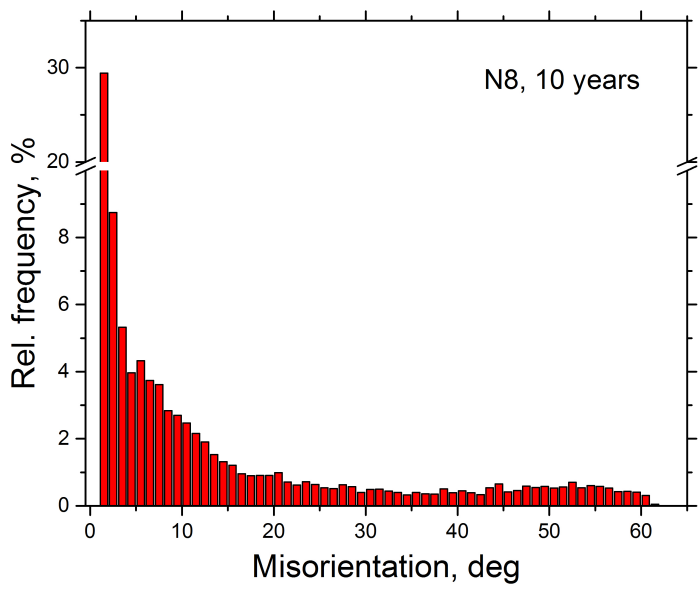

(b)

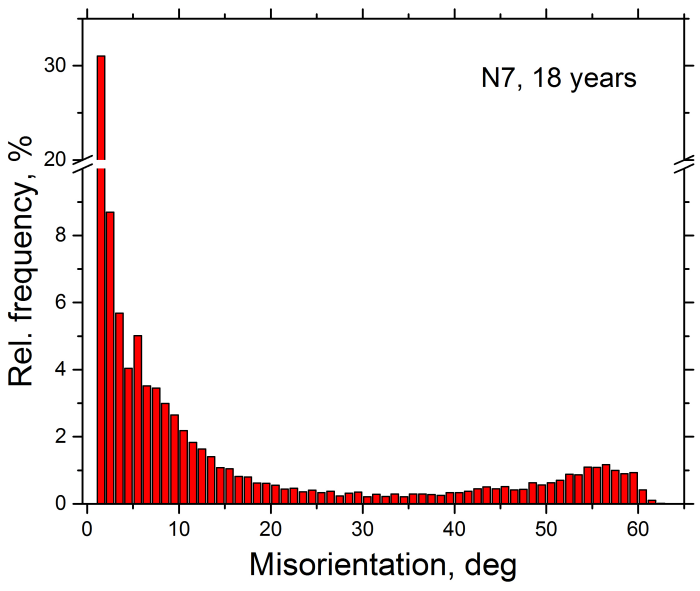

(c)

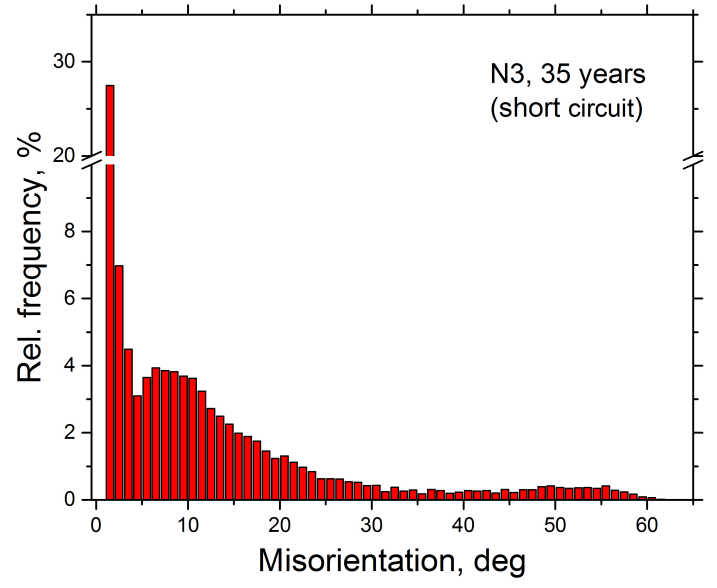

(d)

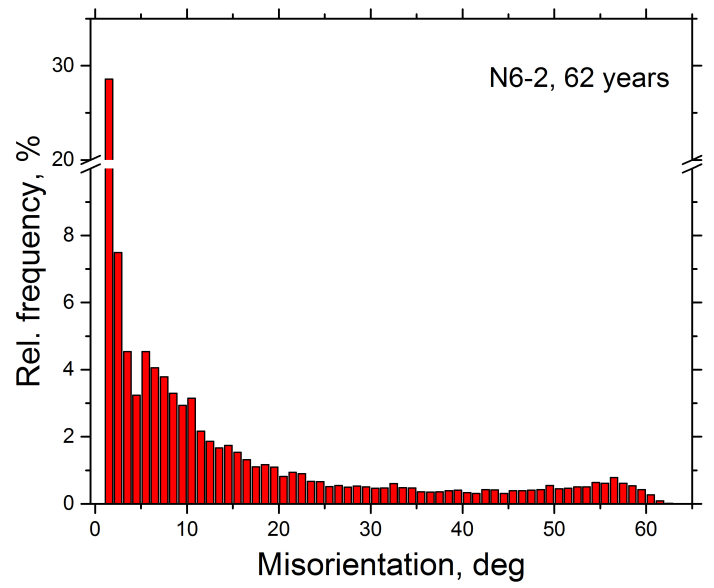

(e)

Figure 11. Histograms of grain boundary misorientation angle distribution for samples with different service life: (a) N5 (0 years), (b) N8 (10 years), (c) N7 (18 years), (d) N3 (35 years and short circuit), and (e) N6-2 (62 years).

\subsection{Results of Elastoplastic and Densitometric Measurements}

Figure 12 shows the amplitude dependencies of Young's modulus $E$ and decrement $\delta$ for wire samples of the A50 type. The dependencies $E(\varepsilon)$ and $\delta(\varepsilon)$ were measured sequentially with an increase and decrease in the amplitude of vibrational deformation $\varepsilon$. When analyzing the data, it can be seen that for sample N8 (10 years of service), there is a noticeable decrease in Young's modulus $E$ relative to the state of the fresh wire (N5) from, respectively, 72.2 to $69.8 \mathrm{GPa}$. Note that an increase in the service life leads to a sequential 
increase in the modulus, and its highest value ( $E=72.6 \mathrm{GPa})$ is typical for sample N6-2 after 62 years of operation.

Figure 12 also presents experimental data for the amplitude dependency of internal friction (logarithmic decrement $\delta(\varepsilon)$ ). The close values of the decrement for the samples N5 (0 years of service) and N3 (35 years of service), $\delta=27 \cdot 10^{-5}$ and $\delta=23 \cdot 10^{-5}$, respectively, seem natural in view of the fact that the sample N3 was for a long time at a high temperature as a result of a short circuit. For sample N7 (18 years of operation), a noticeable increase in $\delta$ up to $85 \cdot 10^{-5}$ is observed. The highest value of the decrement is characteristic of sample N8 (10 years of operation), $\delta>450 \cdot 10^{-5}$. In the studied sample N6-2 with a service life of 62 years, the decrement returns to the value $\delta=23 \cdot 10^{-5}$, close to the $\delta$ values in samples N3 (35 years of service life, short circuit) and N5 (fresh).

For samples N5 (0 years of service life), N7 (18 years), N3 (35 years, short circuit), and N6-2 (62 years), a similar behavior is observed for the modulus and decrement changes: their values are close and vary near $E=72.6 \mathrm{GPa}$ and within $\delta=23 \cdot 10^{-5}-85 \cdot 10^{-5}$. A decrease in the elastic modulus to $E=69.8 \mathrm{GPa}$ for sample N8 (10 years) is accompanied by a significant increase in the decrement $\left(\delta \approx 450 \cdot 10^{-5}\right)$.

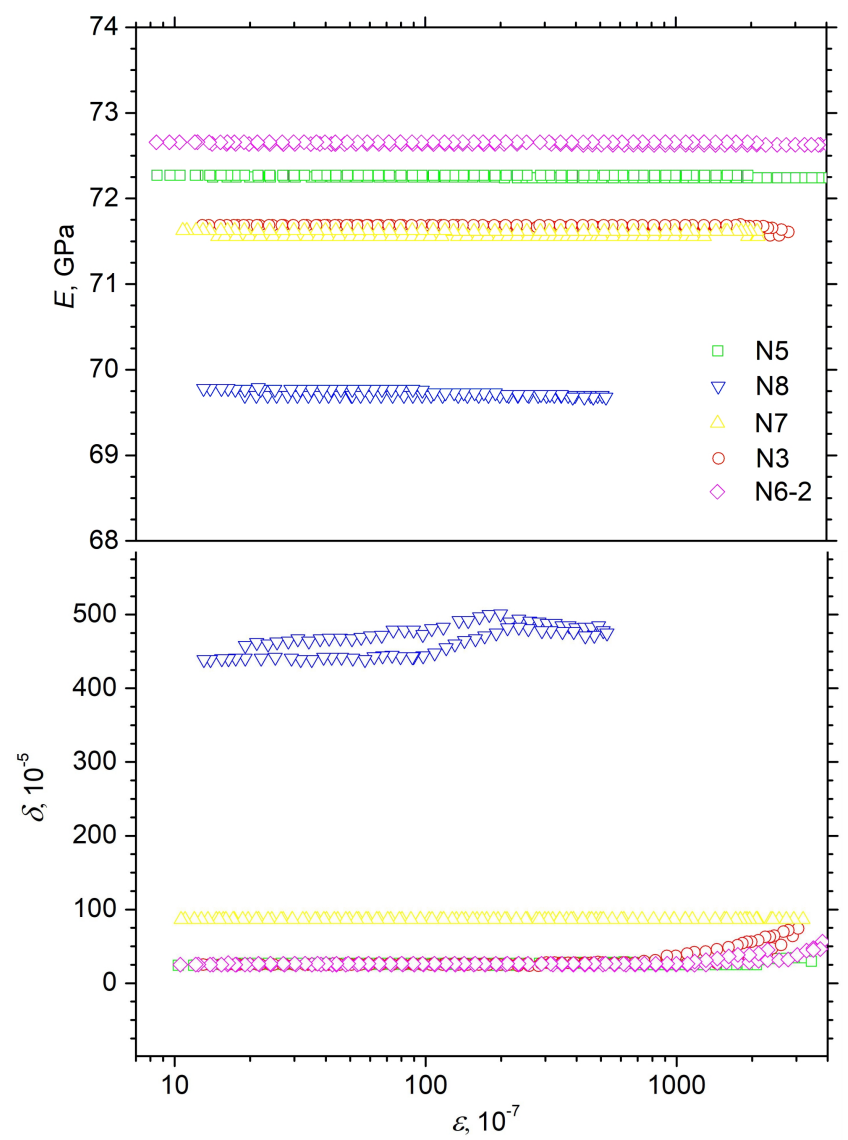

Figure 12. Dependencies of Young's modulus $\mathrm{E}$ and decrement $\delta$ of the $\mathrm{Al}$ material of wire samples on the amplitude $\varepsilon$ of vibrational deformation. Sample numbers according to Table 1 are also shown. Measurements were performed at room temperature.

Figure 13 presents the diagrams of acoustic (microplastic) deformation $\sigma\left(\varepsilon_{d}\right)$ obtained from the dependencies $E(\varepsilon)$ shown in Figure 12 and taken at the first increase in the amplitude. One can see from these diagrams that the highest value of $\sigma_{s}=14.0 \mathrm{MPa}$ corresponds to the fresh state (N5) of the wire (hereinafter in the comparisons, the values of the conditional limit of the micro-flow $\sigma=\sigma_{s}$ are given at the value of inelastic deformation $\varepsilon_{d}=3 \cdot 10^{-8}$ ). As for the character of the change in the conditional limit of micro-flow, we can note here, as in the case of a change in Young's modulus, some trend with an increase 
in the service life. After operation for 10 years (sample N8), there is a decrease in the conditional limit of micro-flow by almost 5 times, to $\sigma_{S}=2.3 \mathrm{MPa}$. The increase in service life leads to a consistent moderate increase in $\sigma_{\mathcal{S}}$ to $7.3 \mathrm{MPa}$ and $13.1 \mathrm{MPa}$ after 18 and 62 years, respectively. It can be especially noted that after a short circuit (sample N3), the micro-flow limit became $\sigma_{s}=11.9 \mathrm{MPa}$, which is close to the new (unexploited) state of the wire. Note also that, as a result of acoustic deformation of the samples, the absolute values of inelastic deformations are tens of nanometers (see Figure 13).

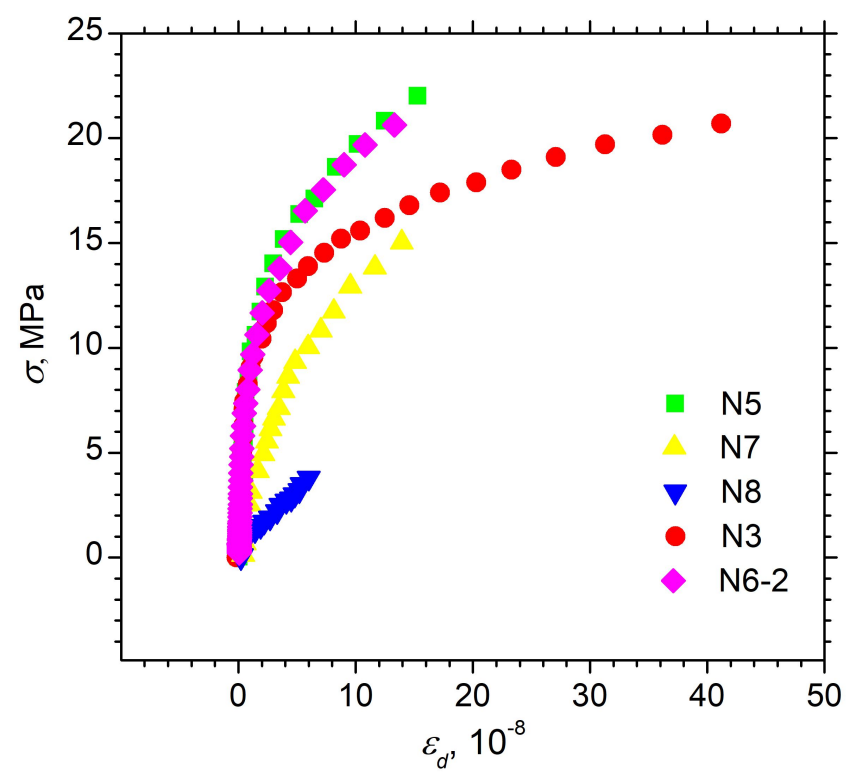

Figure 13. Diagrams of microplastic deformation $\sigma\left(\varepsilon_{d}\right)$ of Al wire samples. Sample numbers are given according to Table 1.

For a more convenient data analysis, the characteristics of elastic $\left(E\right.$ and $\left.\delta_{i}\right)$ and microplastic $\left(\sigma_{s}\right)$ deformations are presented in Table 3, where the data on the change in density $\rho_{d}$ obtained experimentally in densitometric measurements are also indicated.

The highest density value corresponds to the new (unexploited) state of the wire (N5), $\rho_{d}=2.6949 \mathrm{~g} / \mathrm{cm}^{3}$ (e.s.d. on the last digit, $\sim 0.0003 \mathrm{~g} / \mathrm{cm}^{3}$ ), Table 3 and Figure $5 \mathrm{c}$. When the service life is 10 years (sample N7), the integral density value decreases to $2.6906 \mathrm{~g} / \mathrm{cm}^{3}$, and the absolute value of the density defect $\Delta \rho / \rho_{d}$ (where $\Delta \rho=\rho_{d}-\rho_{d N 5}$ ) is equal to $0.16 \%$. The increase in the service life from 10 to 18 years (N8) does not lead to any change in density $\left(\rho_{d}=2.6905 \mathrm{~g} / \mathrm{cm}^{3}\right)$. After the short circuit (N3), the lowest density value among all the samples under study is revealed, $\rho_{d}=2.6885 \mathrm{~g} / \mathrm{cm}^{3}$. After 62 years (N6-2), the density value is practically the same as for the sample without operation, $\rho_{d}=2.6939 \mathrm{~g} / \mathrm{cm}^{3}$.

Table 3. Densities $\rho_{d}$ according to the results of densitometric measurements, Young's modulus $E$, amplitude-independent decrement $\delta_{i}$, and conditional limit of micro-flow $\sigma_{s}$ at inelastic deformation $\varepsilon_{d}=3.0 \cdot 10^{-8}$. The e.s.d.s of all values are at the last digit after the floating point.

\begin{tabular}{cccccc}
\hline Sample $N$ & Service Life, Years & $\rho_{\boldsymbol{d}}, \mathbf{g} / \mathbf{c m}^{\mathbf{3}}$ & $\boldsymbol{E}, \mathbf{G P a}$ & $\delta_{\boldsymbol{i}}, \mathbf{1 0}^{-\mathbf{5}}$ & $\sigma_{\boldsymbol{s}}, \mathbf{M P a}$ \\
\hline 5 & 0 & 2.6949 & 72.2 & 27 & 14.0 \\
\hline 8 & 10 & 2.6906 & 69.8 & 457 & 2.3 \\
\hline 7 & 18 & 2.6905 & 71.6 & 85 & 7.3 \\
\hline 3 & 35 & 2.6885 & 71.6 & 23 & 11.9 \\
\hline $6-2$ & 62 & 2.6939 & 72.6 & 23 & 13.1 \\
\hline
\end{tabular}




\section{Discussion}

Thus, the analysis of single wires from multi-wire strands of single-thread cables (A50 type, without isolation and steel core) of the overhead power lines by XRD methods showed that, in the near-surface layer of the wires with a depth of $\sim 36 \mu \mathrm{m}$, the operation time $(t)$ dependency of the structure parameters (cubic unit cell parameter $a$ of the $\mathrm{Al}$ material of the wire), and the microstructure parameters extracted from XRD data (average crystallite size $D$ and absolute average value of microdeformation $\varepsilon_{S}$ in them) show a similar growth pattern (Figures $5 \mathrm{a}$ and $7 \mathrm{a}, \mathrm{b}$ ) to a maximum at $t=10$ years for $D(t)$, between $t=10$ years and $t=18$ years for $\varepsilon_{S}(t)$ and $t=18$ years for $a(t)$. An increase in the $\mathrm{Al}$ unit cell parameter $a$ is accompanied by a decrease in the average density $\rho$ of the near-surface layer (Figure 5c). With an increase in the service life up to 62 years, the sample shows parameters comparable to the sample after 10 years of service, which is possibly associated with the relaxation of $\mathrm{Al}$ due to the oxidation of the near-surface layer with the formation of $\delta$ - and /or $\delta^{*}$-oxides of $\mathrm{Al}$ (Figures $2 \mathrm{~d}$ and 6 ), characterized by a significantly higher mass density than Al.

The integral mass density $\rho_{d}$ obtained in densitometric measurements, which is a characteristic of the entire sample, shows values close to the densities of the near-surface layer $\rho_{x}$ calculated from XRD structural data, although slightly lower (Tables 2 and 3 , Figure $5 b$ ). Probably, the lower values of the density $\rho_{d}$ are associated with the lesser influence of the thin oxidized near-surface layer during densitometric measurements. However, the change in the absolute values of the density defect $\Delta \rho / \rho$ is very close in both cases (Figure 5c). The maximum absolute value of the density defect for the nearsurface layer in samples without damage (according to calculations from XRD data) and for the entire sample (according to the results of densitometric measurements) is achieved after 18 years of service and has very close values (respectively, $\Delta \rho_{x} / \rho_{x} \approx-0.17 \%$ and $\Delta \rho_{d} / \rho_{d} \approx-0.16 \%$ ). All trends in the evolution over time of the integral density $\rho_{d}$ and density defect $\Delta \rho_{d} / \rho_{d}$ and the cubic unit cell parameter calculated from $\rho_{d}$ for samples without damage during service remain the same as the corresponding parameters obtained from XRD data for the near-surface layer (Figure $5 a-c$ ).

The main difference is observed for sample N3 after the short circuit. The relaxation of the structural and microstructural parameters of the near-surface layer in sample N3 after 35 years of operation can be associated not with the effect of aging time during the exploitation but rather with the fact that this sample was cut out of the wire after a short circuit and exposure to temperature as a result of fire. Perhaps, despite the fact that the sample was cut from a piece removed at a distance of $\sim 1.6 \mathrm{~m}$ from the damaged areas, there was relaxation of both its microstructure and structure. The disappearance (or at least a significant decrease) of the effects of preferred orientation in this sample, apparently, can also be associated with the relaxation of the microstructure and structure of the wire under the action of a short circuit and temperature. For a final clarification of this issue, it is necessary to study a wire without damage with a comparable service life of $\sim 35$ years. If, according to XRD data, the parameters of the near-surface layer relax to values close to those in the fresh wire, then according to the results of densitometry in the volume of the wire, density $\rho_{d}$ is much less than in the new wire and the absolute value of the density defect increases to $\Delta \rho_{d} / \rho_{d} \approx 0.24 \%$ (Figure $5 c$ ). Probably, the temperature and other factors during a short circuit have a different effect on the state of the near-surface layer and the material in depth. Defects on the surface are annealed, resulting in the formation of an $\mathrm{Al}$ material with equilibrium characteristics and lack of preferred orientation, while in the depth the number of defects, microcracks, and voids increases and a reduction of the material density is observed.

The development of microdeformations $\varepsilon_{S}$ in $\mathrm{Al}$ crystallites during exploitation can be, for example, due to the fact that wires stretch over time due to sagging of the cables and environmental impact. An increase in the parameter $a$ of the unit cell and in the size of crystallites $D$ as well as a decrease in the average density of $\mathrm{Al}$ material in the near-surface layer and in the bulk of the samples can also be associated with this, although 
the influence of electric voltage cannot be excluded. The development of the preferred orientation along [011], which was also observed in the sample before operation (sample N5-2), to a maximum in wires after 18 years of service (N7) is apparently the result of an increase in crystallite size according to XRD results and an increase in grain size (which are composed of crystallites) and their general alignment according to EBSD data. Since crystallites are characterized by this preferred orientation, these factors lead to an increase in the maximum intensities of the 022 reflection.

According to the XRD data, fresh wire samples of both A50 type and AC50, one without and one with a steel wire-core, are characterized by similar values of structure and microstructure parameters.

Let us move on to the analysis and discussion of the elastic and microplastic properties of wires during their operation. First of all, it is worth noting several microstructural factors affecting the elastic and inelastic properties of metals, which are considered in the literature. Among the main factors that determine the modulus of elasticity in metals, there are porosity, crystallographic texture, and non-equilibrium state of grains [41-46]. In addition, one can note the role of internal stresses, the formation of which leads to an increase in the elastic modulus [47,48].

The decrease in Young's modulus $E$ during operation from 0 to 10 years (Table 3, Figure 12a) seems logical. Indeed, according to densitometric and XRD data (Tables 2 and 3, Figure $5 b$ ), the density of the samples noticeably decreases after 10 years, which can only be explained as a result of the formation of defects of a void nature (cracks, pores), which lead to a drop in $E$. When analyzing the data on the change in Young's modulus, the question arises as to the cause of an increase in the modulus in the period from 10 to 18 years (Figure 12a), despite the fact that the magnitude of the density defect (i.e., the magnitude of the density reducing) according to the results of densitometric measurements is the same and amounts to $\approx 0.16 \%$, and according to XRD results in the near-surface layer it increases from $0.09 \%$ to $0.17 \%$ (Figures $5 \mathrm{c}$ ). One of the possible factors leading to an increase in the modulus is the influence of long-range fields of high internal stresses (through elastic constants of higher orders). It is known that overhead power lines are under the influence of various kinds of mechanical loads, namely operational ones (tensions), wind ones (fatigue loadings), etc. All these influences lead to structural transformations affecting the studied properties. The XRD data (see Figure $7 \mathrm{~b}$ ) show that an increase in the average values of microstrain $\varepsilon_{s}$ continues over a time interval of 10 to 18 years. This may indicate that high internal stresses are formed in the wire structure since their appearance leads to an increase in Young's modulus E. Another important factor is the effect of the crystallographic texture, the enhancement of which is especially pronounced in the interval from 0 to 18 years of service (Figure 3). Besides, the formation of aluminum oxides was detected, the volume fraction of which is gradually increasing (Figure 6). According to the literature, the elastic modulus for $\mathrm{Al}_{2} \mathrm{O}_{3}$ is $E=365$ to $393 \mathrm{GPa}$ [49], i.e., significantly more than the Young's modulus of $\mathrm{Al}, E \sim 70 \mathrm{GPa}$; therefore, the formation of such a layer contributes to the increase in the modulus of the wires.

When analyzing the change in the elastic modulus for sample N3 (35 years of service), it is necessary to take into account that it was exposed to a sufficiently high temperature for a long enough time (there was a destruction due to a short circuit). On the one hand, it has been found that according to densitometric measurements the integral density defect value for this state is the maximum absolute value $\Delta \rho_{d} / \rho_{d} \approx-0.24 \%$, which should lead to a decrease in the modulus (compared, e.g., with the sample N7, 18 years of service). On the other hand, as follows from the data of Table 3, the $E$ values for these samples are the same and equal to $E \approx 71.6 \mathrm{GPa}$. Nevertheless, as noted above, there is one more factor affecting the magnitude of the elastic modulus, namely the dislocation structure. Indeed, the theory of dislocation internal friction [34] explains an increase in the elastic modulus $E$ and $a$ decrease in the decrement $\delta_{i}$ upon annealing by the diffusion of point defects to dislocations. Defects fix dislocations, their mobility becomes less, and dislocation 
deformation becomes more awkward. This affects both $E$ and $\delta_{i}$ so that Young's modulus increases and the decrement decreases.

As can be seen from the analysis of the data of Table 3 and Figure 12, the value of modulus $E$ in sample N6-2 (62 years of operation) remains at a high level, even higher than that for the fresh N5 wire. It has already been noted that the modulus $E$, when measured with high accuracy, is very sensitive parameter of a material structure. From this point of view, it can be stated that for the N6-2, according to structural studies, relaxation of microstructure parameters is observed. The higher value of the integral density of the N6-2 sample (in comparison with other wires, which were studied after exploitation) is possibly due to a noticeable oxidation of the surface of these wires with the formation of the $\mathrm{Al}_{2} \mathrm{O}_{3}$ oxides, whose density, as recently mentioned, is significantly higher than that of Al. This assumption is supported by the fact that the tabular values of the Young's modulus $E$ for $\mathrm{Al}_{2} \mathrm{O}_{3}$ are several times higher than for the modulus $\mathrm{Al}$ [49], as marked in the above text, which also explains the increase in E when the service life increases from 10 to 62 years (Figure 12, Table 3). In addition, the crystallographic texture is enhanced for the entire period of operation (Figure 3). In general, we see a complex multifactorial influence on the modulus and it is difficult to single out the role of a particular circumstance.

The high value of the decrement for sample N8 after 10 years of service can be explained from the point of view of the above-mentioned theory that considers the interaction of dislocations with point defects [34], according to which, when dislocations are introduced into the sample, the decrement $\delta_{i}$ should increase. During the service life of the wires, the density of dislocations may increase due to various mechanical influences and plastic deformations that the wires undergo during operation, thus increasing the decrement.

The data obtained indicate that exploitation leads to a decrease in the micro-flow limit $\sigma_{s}$. On the contrary, there is the increase in $\sigma_{s}$ for the N3 sample relative to other exploited wires, which is probably a result of structure relaxation after annealing due to a short circuit, as noted above (see Section 3.2, XRD results).

\section{Conclusions}

The single Al wires from the cables of overhead power lines of different service life consisting of a single non-isolated (bare) multi-wire strand of six $\mathrm{Al}$ wires without steel core were investigated by techniques of XRD, SEM, EDX, EBSD, densitometry, and acoustic-resonance method.

It was found that the characteristics of elastic and microplastic deformations, which are characteristics of the entire volume of the wire, are sensitive to the changes in the structure and microstructure and indicate complex structural changes correlating with the results obtained by diffraction methods.

The Young's modulus shows a noticeable decrease by $\approx 3.3 \%$ already after 10 years of service (from $E=72.2 \mathrm{GPa}$ in the new sample and $69.8 \mathrm{GPa}$ in the 10-year wire). This reduction of $E$ is accompanied by a significant increase of amplitude-independent decrement $\delta_{i}$ by $\sim 17$ times (from $27 \cdot 10^{-5}$ to $457 \cdot 10^{-5}$ ) and a decrease of the microplastic flow stress $\sigma_{s}$ by $\sim 7$ times (from $14.0 \mathrm{MPa}$ to $2.3 \mathrm{MPa}$ ). Structural and microstructural parameters averaged over the total X-ray penetration depth of $\approx 36 \mu \mathrm{m}$ of the near-surface layer show the maximum values of changes in absolute magnitude only after 18 years of service. Calculated from XRD structural data, the decrease in the mass density of the near-surface layer reaches value of $-0.17 \%$ in terms of density defect $\Delta \rho_{x} / \rho_{x}$, which is close to the decrease of the density $\Delta \rho_{d} / \rho_{d}=-0.16 \%$ in the bulk of the wires according to densitometric results. These changes of elastic, microplastic, structural,and microstructural properties are associated with the formation of microvoids in the near-surface region and in the bulk of the wires.

Relaxation of the elastic and microplastic characteristics to the values close to the new wires during the service life of wires from 10 to 62 years (and relaxation of the structural and microstructural parameters in the sample with a long service life of 62 years to a level comparable to wires with the 10 -years service life) is due to a combination of factors, which 
are caused by wire stretching owing to both cable sagging and environmental impact during long time (at least, more than $\sim 10$ years) operation under high electric voltage. According to structural studies by XRD and EBSD methods, the relaxation is associated with an increase in the crystallographic texture, accompanied by growth of crystallites (from $\sim 100 \mathrm{~nm}$ in new wire to $\sim 250 \mathrm{~nm}-300 \mathrm{~nm}$ sizes after operation) and grains (from $\sim 1 \mu \mathrm{m}-3 \mu \mathrm{m}$ in new wire to $\sim 3.5 \mu \mathrm{m}-5 \mu \mathrm{m}$ sizes after operation), an increase in internal local stresses (microstrains increase in absolute magnitude from $\varepsilon_{s} \sim 0 \%$ in new wires up to $0.030 \%$ in wires after operation), and the formation of $\mathrm{Al}$ oxides on the surface ( $\sim 0.7 \mathrm{vol} . \%$ of crystalline $\delta$ - and /or $\delta^{*} \mathrm{Al}$ oxides is formed in the 62-years sample compared to 0 vol. \%. $-\sim 0.2$ vol. $\%$ in new and 10-years wires, respectively).

The results obtained for a new (unexploited) sample without operation can be used when studying wires of both types, A50 and AC50 (respectively, without and with steel core), since they show similar values of the parameters of the structure and microstructure.

Supplementary Materials: The following are available online at https:/ / www.mdpi.com/article/10 $.3390 /$ met11121955/s1, Figure S1: Setups of (a) EBSD and (b) XRD measurements and (c) schematic diagram of the acoustic experiment control system. Figure S2: EDX spectra of the samples (a) N8 (A50, 10 years), (b) N7 (A50, 18 years) and (c) N3 (A50, 35 years, after short circuit). Figure S3: (a) XRD pattern of sample N8 and (b) part of the XRD pattern of sample N3 in an enlarged scale. Figure S4: XRD pattern of sample N5 (new) of AC50 type. Figure S5: Tabular XRD pattern of Al according to PDF-2 card 01-073-9843. Figure S6: The dependency of the average sizes D of crystallites of the $\mathrm{Al}$ wires of cables of the overhead power lines on the service life $t$ in the model on the service life $\mathrm{t}$ in the model without microstrains $\left(\varepsilon_{S}=0\right)$. Figure S7: WHP $(\mathrm{a}-\mathrm{e})$ and SSP $(\mathrm{f}-\mathrm{j})$ graphs for Al reflections of the wires of the A50 type cables of the overhead power lines. Figure S8: WHP (a) and SSP (b) graphs for Al reflections of the new wire of the AC50 type cable of the overhead power lines. Table S1: Reflections of possible $\mathrm{Al}_{2} \mathrm{O}_{3}$ crystalline phase observed in $\mathrm{Al}$ wire samples.

Author Contributions: A.A.L., investigation (XRD), methodology, validation, project administration, data curation, formal analysis, writing - original draft preparation, writing-review and editing; M.V.N., investigation (densitometry and acoustic), methodology, validation, formal analysis, data curation, writing —original draft preparation; A.I.L., investigation (SEM, EDX, EBSD), methodology, formal analysis, data curation, writing —original draft preparation; B.K.K., investigation (acoustic), methodology, formal analysis, data curation; A.G.K., investigation (acoustic), methodology, formal analysis, data curation; P.N.B., supervision, conceptualization, methodology, funding acquisition; A.G.P., writing — original draft preparation, conceptualization; N.D.P., project administration, conceptualization; M.M.S., conceptualization, resources, V.N.K., conceptualization, resources; V.N.T., conceptualization, resources, funding acquisition. All authors have read and agreed to the published version of the manuscript.

Funding: This research was funded by the state assignment of Russian Federation No. 0720-2020-0025 "Development of methods and analysis of ways to achieve a high level of safety and competitiveness of objects of energy systems based on digital technologies".

Data Availability Statement: The data presented in this study are available on request from the corresponding author.

Acknowledgments: The work was carried out using the equipment and software of the Center of Joint Use "Materials Science and Diagnostics in Advanced Technologies" (Ioffe Institute, St. Petersburg, Russia).

Conflicts of Interest: The authors declare no conflict of interest. 


\section{Abbreviations}

The following abbreviations and nomenclature are used in this manuscript:

\begin{tabular}{|c|c|}
\hline AAAC & All Aluminum Alloy Conductor \\
\hline ACSR & Aluminum Conductor Steel Reinforced \\
\hline a.m.u. & atomic mass unit \\
\hline CSAs & coherent scattering areas \\
\hline EBSD & electron backscattering diffraction \\
\hline EDX, EDS & energy-dispersive $\mathrm{X}$-ray microanalysis \\
\hline e.s.d., e.s.d.s & estimated standard deviation(s) \\
\hline $\mathrm{OM}$ & optical Microscopy \\
\hline PDF-2 & Powder Diffraction File-2 \\
\hline $\mathrm{pV}$ & pseudo-Voigt \\
\hline SEM & scanning electron microscopy \\
\hline SSP & size-strain plot \\
\hline WHP & Williamson-Hall plot \\
\hline XRD & X-ray diffraction \\
\hline i.e. & Latin "id est" \\
\hline etc. & Latin "et cetera" \\
\hline cf. & Latin "confer" \\
\hline FWHM & full width at half-maximum of XRD reflection \\
\hline E & Young's modulus (modulus of elasticity) \\
\hline$\delta_{i}$ & amplitude-independent decrement of the material \\
\hline$\delta_{h}$ & non-linear amplitude-dependent absorption of the material \\
\hline$\delta$ & decrement of material (sum of $\delta_{i}$ and $\delta_{h}$ ) \\
\hline$\sigma_{s}$ & microplastic flow stress \\
\hline$h k l$ & Miller indices \\
\hline$d_{h k l}$ & interplane distance corresponding to $h \mathrm{kl}$ reflection \\
\hline $2 \theta$ & diffraction angle \\
\hline$\theta$ & half a diffraction angle \\
\hline $2 \theta$-theta & XRD scanning regime \\
\hline $2 \theta_{o b s}$ & observed Bragg andgle of XRD reflection \\
\hline $2 \Delta \theta_{\text {zero }}$ & correcting shift of the zero of the counter \\
\hline$\Delta 2 \theta_{\text {displ }}$ & displacement correction \\
\hline$I_{\max }$ & maximum intensity of XRD reflection \\
\hline$I_{\min }$ & integral intensity of XRD reflection \\
\hline$D$ & average size of crystallites \\
\hline$\varepsilon_{S}$ & absolute value of average magnitude of microstrains \\
\hline$\varepsilon$ & vibrational deformation amplitude \\
\hline$\varepsilon_{d}$ & non-linear inelastic deformation \\
\hline$K_{\text {Scherrer }}$ & coefficient in Scherrer equation \\
\hline$K_{\text {strain }}$ & coefficient in Wilson-Stokes equation \\
\hline$B_{\text {int }}$ & integral width of XRD reflection \\
\hline$\lambda$ & wavelength \\
\hline$R_{\text {cod }}$ & determination coefficient \\
\hline e & Euler's number \\
\hline$T$ & temperature \\
\hline$T_{p e n}$ & penetration depth \\
\hline$\mu_{l}$ & the linear absorption coefficient of material \\
\hline$\rho$ & density of material \\
\hline$\rho_{x}$ & density of material calculated according to XRD structural data \\
\hline$\rho_{d}$ & density of material measured in densitometry experiment \\
\hline$\delta \rho_{x} / \rho_{x}$ & relative error of $\rho_{x}$ \\
\hline$\delta \rho_{d} / \rho_{d}$ & relative error of $\rho_{d}$ \\
\hline$(\Delta E / E)_{h}$ & defect of the Young's modulus \\
\hline$\delta E / E$ & the relative error of $E$ \\
\hline$\Delta \rho / \rho$ & magnitude of the density defect \\
\hline
\end{tabular}




$\begin{array}{ll}\rho_{\text {table }} & \text { tabulated value of } \rho \\ f & \text { resonance frequency } \\ \sigma & \text { oscillatory stress amplitude (Acoustic (microplastic) deformation) } \\ t & \text { service life } \\ V_{\text {cell }} & \text { volume of the cell } \\ a & \text { unit cell parameter } \\ \sigma_{S} & \text { microplastic flow stress (micro-flow limit) }\end{array}$

\section{References}

1. Shahid, M.A.; Khan, T.M.; Zafar, T.; Hashmi, M.F.; Imran, M. Health diagnosis scheme for in-service low voltage Aerial Bundled Cables using super-heterodyned airborne Ultrasonic testing. Electr. Power Syst. Res. 2020, 180, 106162. [CrossRef]

2. Kalombo, R.; Martínez, J.; Ferreira, J.; da Silva, C.; Araújo, J. Comparative Fatigue Resistance of Overhead Conductors Made of Aluminium and Aluminium Alloy: Tests and Analysis. Proc. Eng. 2015, 133, 223-232. [CrossRef]

3. Kul'kov, V.; Sultanov, M.; Kuryanov, V.; Sh, N.D. Electrical reliability simulation based on analysis of fatigue strength of overhead line wires. In Proceedings of the 3rd International Youth Conference on Radio Electronics, Electrical and Power Engineering (REEPE), Moscow, Russia, 11-13 March 2021; p. 9388090. [CrossRef]

4. Dinmohammadi, F.; Flynn, D.; Bailey, C.; Pecht, M.; Yin, C.; Rajaguru, P.; Robu, V. Predicting Damage and Life Expectancy of Subsea Power Cables in Offshore Renewable Energy Applications. IEEE Access 2019, 7, 54658-54669. [CrossRef]

5. Radulescu, C.; Ionica, I.; Stihi, C.; Popescu, I.V.; Poinescu, A.A.; Suica-Bunghez, I.R. The behavior of underground power cables under the action of stress factors. Rom. J. Phys. 2014, 59, 1150-1159.

6. Xia, R.; Meng, S.; Wang, Y. Long Term Reliability Tests of 500 kV XLPE Cable System. In Proceedings of the 2014 International Conference on Power System Technology, Chenghu, China, 20-22 October 2014; No. CP2377.

7. Yamanaka, S.; Fukuda, T.; Ito, K.; Tomita, J.; Seguchi, T. Use of Residual Voltage for Diagnosis of Electric Power Cables Used in Nuclear Power Stations. Electr. Eng. Jpn. 1997, 119, 18-24. [CrossRef]

8. Brettschneider, S.; Fofana, I. Evolution of Countermeasures against Atmospheric Icing of Power. Energies $2021,14,6291$. [CrossRef]

9. Lu, J.; Hu, J.; Fang, Z.; Qiao, X.; Zhang, Z. Electric Field Distribution and AC Breakdown Characteristics of Polluted Novel Lightning Protection Insulator under Icing Conditions. Energies 2021, 14, 7493. [CrossRef]

10. Cintula, B.; Eleschova, Z.; Cenky, M.; Janiga, P.; Bendík, J.; Belan, A. Three-Phase and Single-Phase Measurement of Overhead Power Line Impedance Evaluation. Energies 2021, 14, 6314. [CrossRef]

11. Byakov, A.V.; Eremin, A.V.; Shah, R.T.; Burkov, M.V.; Lyubutin, P.S.; Panin, S.V.; Maruschak, P.O.; Menou, A.; Bencheikh, L. Estimating mechanical state of AA2204 specimen under tension with the use of Lamb wave based ultrasonic technique. Mol. Cryst. Liq. Cryst. 2017, 655, 94-102. [CrossRef]

12. Ning, Y.; Wang, D.; Li, Y.; Zhang, H. Location of Faulty Section and Faults in Hybrid Multi-Terminal Lines Based on Traveling Wave Methods. Energies 2018, 11, 1105. [CrossRef]

13. Zagulyaev, D.V.; Konovalov, S.V.; Yaropolova, N.G.; Ivanov, Y.F.; Komissarova, I.A.; Gromov, V.E. Effect of the Magnetic Field on the Surface Morphology of Copper upon Creep Fracture. J. Surf. Investig. X-ray Synchrotron Neutron Tech. 2015, 9, 410-414. [CrossRef]

14. Alshwawreh, N.; Alhamarneh, B.; Altwarah, Q.; Quandour, S.; Barghout, S.; Ayasrah, O. Electrical Resistivity and Ten sile Strength Relationship in Heat-Treated All Aluminum Alloy Wire Conductors. Materials 2021, 14, 5738. [CrossRef] [PubMed]

15. Xu, X.; Yu, Z.; Li, Y.; Wang, W.; Xu, L. Microstructural Study of Arc Beads in Aluminum Alloy Wires with an Overcurrent Fault. Materials 2021, 14, 4133. [CrossRef] [PubMed]

16. Kreislova, K.; Jaglova, M.; Turek, L.; Koukalova, A. Evaluation of corrosion of long-termexposed aluminium conductor. Koroze Ochr. Mater. 2013, 57, 25-34. [CrossRef]

17. Azevedo, C.R.F.; Cescon, T. Failure analysis of aluminum cable steel reinforced (ACSR) conductor of the transmission line crossing the Paranar River. Eng. Fail. Anal. 2002, 9, 645-664. [CrossRef]

18. de la Fuente, D.; Otero-Huerta, E.; Morcillo, M. Studies of long-term weathering of aluminium in the atmosphere. Corros. Sci. 2007, 49, 3134-3148. [CrossRef]

19. Taylor, G.I. The mechanism of plastic deformation of crystals. Proc. R. Soc. A 1934, 145, 362-387. [CrossRef]

20. Orowan, E. Zur Kristallplastizität. III. Z. Phys. 1934, 89, 634-659. (In German) [CrossRef]

21. Read, T.A. The Internal Friction of Single Metal Crystals. Phys. Rev. 1940, 58, 371-380. [CrossRef]

22. Kardashev, B.; Chernov, V. Internal friction and impact toughness of structural BCC alloys. Mater. Sci. Eng. A 2009, 521-522, 329-334. [CrossRef]

23. Kardashev, B.; Kupriyanov, I. Micro- and Macro-Plastic Properties of Be Polycrystals. Sol. Stat. Phenom. 2012, 184, 257-262. [CrossRef]

24. Diffrac.Suite Eva, Version 5.1.0.5; Brucker AXS: Karlsruhe, Germany, 2019.

25. Fawcett, T.G.; Kabekkodu, S.N.; Blanton, J.R.; Blanton, T.N. Chemical analysis by diffraction: The Powder Diffraction File ${ }^{\mathrm{TM}}$. Powder Diffr. 2017. 32, 63-71. [CrossRef] 
26. Maunders, C.; Etheridge, J.; Wright, N.; Whitfield, H.J. Structure and microstructure of hexagonal $\mathrm{Ba}_{3} \mathrm{Ti}_{2} \mathrm{RuO}_{9} \mathrm{by}_{\mathrm{e}} \mathrm{electron}$ diffraction and microscopy. Acta Cryst. B 2005, 61, 154-159. [CrossRef]

27. Levin, A.A.; Levichkova, M.; Hildebrandt, D.; Klisch, M.; Weiss, A.; Wynands, D.; Elschner, C.; Pfeiffer, M.; Leo, K.; Riede, M. Effect of film thickness, type of buffer layer, and substrate temperature on the morphology of dicyanovinyl-substituted sexithiophene films. Thin Solid Film. 2012, 520, 2479-2487. [CrossRef]

28. Terlan, B.; Levin, A.A.; Börrnert, F.; Simon, F.; Oschatz, M.; Schmidt, M.; Cardoso-Gil, R.; Lorenz, T.; Baburin, I.A.; Joswig, J.O.;

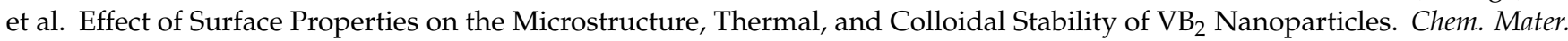
2015, 27, 5106-5115. [CrossRef]

29. Terlan, B.; Levin, A.A.; Börrnert, F.; Zeisner, J.; Kataev, V.; Schmidt, M.; Eychmüller, A. A Size-Dependent Analysis of the Structural, Surface, Colloidal, and Thermal Properties of $\mathrm{Ti}_{1-x} \mathrm{~B}_{2}(x=0.03-0.08)$ Nanoparticles. Eur. J. Inorg. Chem. 2016, 2016, 3460-3468. [CrossRef]

30. Rehani, B.R.; Joshi, P.B.; Lad, K.N.; Pratap, A. Crystallite size estimation of elemental and composite silver nano-powders using XRD principles. Indian J. Pure Appl. Phys. 2006, 44, 157-161.

31. Scherrer, P. Bestimmung der Grose und der inneren Struktur von Kolloidteilchen mittels Rontgenstrahlen. Nachr. Konigl. Ges. Wiss. Gottingen. 1918, 26, 98-100. (In German)

32. Stokes, A.R.; Wilson, A.J.C. The diffraction of X rays by distorted crystal aggregates-I. Proc. Phys. Soc. Lond. 1944, 56, $174-181$. [CrossRef]

33. Langford, J.I. A rapid method for analysing the breadths of diffraction and spectral lines using the Voigt function. J. Appl. Cryst. 1978, 11, 10-14. [CrossRef]

34. Nikanorov, S.P.; Kardashev, B.K. Elasticity and Dislocation Inelasticity of Crystals; Nauka: Moscow, Russia, 1985. (In Russian)

35. Miller, P.H.; DuMond, J.W.M. Tests for the validity of the X-ray crystal method for determining $N$ and $e$ with aluminum, silver and quartz. Phys. Rev. 1940, 57, 198-206. [CrossRef]

36. Tsybulya, S.V.; Kryukova, G.N. New X-ray powder diffraction data on $\delta-\mathrm{Al}_{2} \mathrm{O}_{3}$. Powder Diffr. 2003, 18, 309-311. [CrossRef]

37. Fargeot, D.; Mercurio, D.; Dauger, A. Structural characterization of alumina metastable phases in plasma sprayed deposits. Mater. Chem. Phys. 1990, 24, 299-314. [CrossRef]

38. Otte, H.M.; Montague, W.G.; Welch, D.O. X-ray Diffractometer Determination of the Thermal Expansion Coefficient of Aluminum near Room Temperature. J. Appl. Phys. 1963, 34, 3149-3150. [CrossRef]

39. Slater, J.C. Atomic Radii in Crystals. J. Chem. Phys. 1964, 41, 3199-3204. [CrossRef]

40. Ye, W.; Hohl, J.; Misra, M.; Liao, Y.; Mushongera, L.T. Grain boundary relaxation in doped nano-grained aluminum. Mater. Today Commun. 2021, 29, 102808. [CrossRef]

41. Gremaud, G. Dislocation-Point Defect Interactions. Mat. Sci. Forum. 2001, 366-368, 178-246. [CrossRef]

42. Meyers, M.; Mishra, A.; Benson, D. Mechanical properties of nanocrystalline materials. Progr. Mater. Sci. 2006, 51, 427-556. [CrossRef]

43. Valiev, R.Z.; Aleksandrov, G.V. Nanostructured Metals Produced by Severe Plastic Deformation; English Translation; Logos: Moscow, Russia, 2000; p. 272.

44. Valiev, R.Z.; Aleksandrov, G.V. Bulk Nanostructured Metallic Materials: Preparation, Structure and Properties; Akademkniga: Moscow, Russia, 2007; p. 398. (In Russian)

45. Kardashev, B.K.; Betekhtin, V.I.; Narykova, M.V. Elastoplastic properties of microand submicrocrystalline metals and alloys. Tech. Phys. 2015, 60, 1829-1841. [CrossRef]

46. Kardashev, B.K.; Betekhtin, V.I.; Kadomtsev, A.G.; Narykova, M.V.; Kolobov, Y.R. Elastic and microplastic properties of titanium in different structural states. Tech. Phys. 2017, 62, 1372-1376. [CrossRef]

47. Kardashev, B.K.; Plaksin, O.A.; Stepanov, V.A.; Chernov, V.M. Effect of proton and laser irradiation on the elastic and inelastic properties of a V-Ti-Cr alloy. Phys. Solid State 2004, 46, 1449-1455. [CrossRef]

48. Betekhtin, V.I.; Kadomtsev, A.G.; Kardashev, B.K. Elasticity and inelasticity of microcrystalline aluminum samples having various deformation and thermal histories. Phys. Solid State 2006, 48, 1506-1512. [CrossRef]

49. Martienssen, W.; Warlimont, H. (Eds.) Springer Handbook of Condensed Matter and Materials Data; Springer: Berlin/Heidelberg, Germany, 2005; Chapter 3.2, pp. 431-476. [CrossRef] 